\title{
Notes on Teleostean Ova and Larvae observed at Plymouth in Spring and Summer, 1909.
}

By

A. E. Hefford, B.Sc.

With Plates I and II.

CONTENTS.

Introduction .

Table of Occurrence $\quad 5$

Pelagic Eggs-

Ctenolabrus rupestris $\quad . \quad \cdot 7$

Serranus cabrilla . . 8

Caranx trachurus . 11

Capros aper $\quad .12$

Trachinus vipera . . . . . . . . 13

Trigla . . . 13

Callionymus lyra . $\quad 17$

Pleuronectes $\quad$. 17

Solea vulgaris . $\quad . \quad . \quad . \quad 18$

S. lutea . $\quad . \quad 18$

S. variegata 19

S. lascaris $\quad .20$

Zengopterus $\quad . \quad . \quad 23$

Gadus . $\quad . \quad 29$

G. minutus and G. luseus $\quad . \quad 33$

G. merlangus . .35

Onos (Motella) .

O. mustela . . 37

O. "species A" (? tricirrata $\mathrm{Bl}$, ) _ . . . 38

O. "species B"

Raniceps raninus . . . . . 40

Clupea sprattus . . . . . . . 43

C. pilchardus . . . 44

Demersal Eggs-

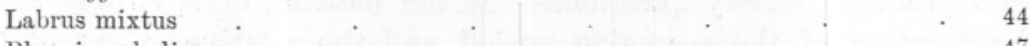

Blennius pholis . . . . . . . . 47

Gobius paganellus . $\quad . \quad$. $\quad . \quad 48$

Lepadogaster bimaculatıs . . . . 49

L. gouani .

Zeus faber . $\quad . \quad 54$

Bibliography . $\quad . \quad 55$

Explanation of Plates . . . . 58

NEW SERIES. - VOL. IX. No. 1 . остOBER, 1910 . A 
THE observations which form the subject of the following notes deal with only part of the total material on which my studies of teleostean reproduction, pursued during the last two years, have been made; but as the other and larger part of the material consists of preserved specimens of the young (chiefly post-larval) stages of fishes collected during the four years 1906 to 1909 inclusive, it is more convenient to deal with the egg collections of the past year first and to treat the whole collection of young fry separately in a further paper.

Systematic examination of tow-nettings for pelagic fish-eggs began on February 11th, and in the early months before the steamer was in commission, owing to the exigencies of weather and time which attend the use of a small sailing-boat, samples were taken only inside the Sound or in its near vicinity. As will be seen from the analysis of the collections given in Table I, there was a break of more than a month's duration, beginning early in March. From April to the end of August the s.s. Oithona was available, which not only rendered collections from the open-sea areas possible, but also permitted the use of the Petersen young-fish trawl, by which large quantities of fish-eggs could be obtained. The quantities so obtained were generally much too large to admit of their individual examination, and therefore it was my practice to pick out a portion of the total eggs for careful examination and frequently for hatching in the laboratory, while the residue was scrutinized as carefully as possible so that the rarer specimens should not be omitted. After a certain amount of practice one can recognize many of the familiar species by size and other peculiarities even with the naked eye, so that after a confirmatory microscopic examination it is possible to obtain a fair knowledge as to the identity of the majority of the species present in a plankton sample, and then exceptional eggs can often-though not, of course, without exception-be discerned. In the case of tow-net samples, which were taken with coarse ( 24 strands to the inch) or medium (50 strands to the inch) nets at various depths from the surface to about 9 or 10 fathoms, care was taken to pick out every individual egg. The hauls were in most cases of 15 minutes' duration, so that quantitative comparison is to some degree possible. Throughout this work I have conducted my observations having in view practical fishery questions-e.g. the locating of spawning areas, the duration of the spawning period, and the relative extent of the breeding of various species of fishes in the Plymouth area-rather than details of purely biological interest, and therefore my records of the characters of eggs and larvae have had special regard to points for purpose of ready identification at the various stages of development; hence details of embryology have little place in this paper. 
The ova and larvae of the majority of species occurring here are already more or less completely known, thanks to the labours of Cunningham, Holt, McIntosh, Masterman, etc., in this country, and to Ehrenbaum and other continental investigators, so that the main object of the descriptive notes which follow is to fill up gaps or to amplify those previous observations which still lack completeness. It is, perhaps, unnecessary to point out that records of such essential diagnostic characters as dimensions, additional to those which have been made on an extensive scale in investigations made in various parts of the North Sea and elsewhere, are of no little importance and value, owing to the local variation which occurs in such respects.

In glancing at the general constitution of my egg samples, as shown in Table I, perhaps the most striking feature is the vast preponderance of those belonging to unmarketable forms. The species which afforded the most numerous pelagic eggs was the rockling, Onos (Motella) mustela, and not far behind this in abundance come the gold-sinny or rockwrasse (Ctenolabrus rupestris), the boar-fish (Capros aper), and the dragonet (Callionymus lyra). Doubtless more eggs of such important families as the Gadidae and Pleuronectidae would have been taken if more off-shore collections had been possible. One may assume that the relative abundance of planktonic eggs, if sufficiently numerous samples are taken, is a fairly reliable index to the proportionate numbers of mature fish occurring in the area under observation at the spawning period. It is therefore to be expected that samples of planktonic eggs from inshore areas should consist predominantly of those from the littoral species of rockling and wrasse.* The same cause, however, does not explain the predominance of dragonets, boarfish, and Norwegian top-knot over such forms as whiting, dab, plaice, and sole, which are marketable fish of much importance to our local trawlers and line fishermen. The general aspect of the case is that species which are regular objects of the trawlers' pursuit are poorly represented in our egg samples. How far trawling itself is responsible for this condition of things is an open question, which in any case it is not in my province to attempt to answer here. But it is a noteworthy fact that the forms mentioned above are of such small size that they would to a great extent escape through the meshes of an ordinary trawl, and therefore stand the best chance of surviving on a well-fished ground. The result cannot be entirely attributed to local distribution of the mature fish, for the Norwegian top-knot has practically the same distribution here as the sole, thickback, "merry-sole,"

* It should be remembered that only one species out of the four Plymouth wrasses (viz. Ctenolabrus rupestris) produces pelagic eggs. 
and dab, as well as approximately the same spawning period, while the same can be said regarding Capros aper as compared with the gurnards.

In the course of my laboratory observations, a point which has struck me as interesting and worthy of further definite inquiry, is the relative vitality of the eggs of various species, as indicated by the extent to which they are affected by the conditions under which they are kept while under observation, in the course of their development in the laboratory. On several occasions I have kept ova of different species in the same vessel of sea-water in order to watch the process of development and examine the hatched-out larvae. In such cases it frequently happened that one species would do well and produce healthy and vigorous larvae, while another would fare badly, and, if the embyro survived so long as to hatch out, the resulting larva would be more or less moribund from the outset and frequently crooked in shape. Notable among those whose vitality in the laboratory was considerable were the eggs and larvae of Motella mustela, Callionymus lyra, and Ctenolabrus rupestris, while those which most often appeared to be adversely affected were Gadus, Trigla, and especially the rare forms Raniceps raninats and Serranus cabrilla. It is to be expected that natural selection has effected that inshore-and sometimes even estuarine-forms like Motella mustela and Ctenolabrus rupestris should produce eggs which are capable of a wider range of environmental change (e.g. of temperature, to take the most obvious factor which operated in the cases under discussion) than those species which spawn in deeper water, where the surrounding conditions are of a more uniform character. In the case of Serranus cabrilla it is not surprising that ova produced in this neighbourhood, which must be at the extreme limit of the natural spawning area of this species, should be of less than average health. The laboratory temperature falls below that of the sea at times in winter, and in summer is generally above it. In the hot weather my vessels containing eggs were put to stand in running aquarium water for the sake of coolness. The same should be done if frost is to be feared in winter. I kept my eggs in sea-water obtained from well outside the Sound, or in aquarium water which had been treated with animal charcoal and then filtered through a "Berkefeld" filter.*

* See Allen and Nelson, "On the Artificial Culture of Marine Plankton Organisms," Journ. M.B.A., Vol. VIII, No. 5, p. 432. 
TABLE I.-SHOWING NUMBER AND PARTICULARS OF CAPTURE OF PELAGIC FISH-EGGS TAKEN OFF PLYMOUTH IN SPRING AND SUMMER, 1909.

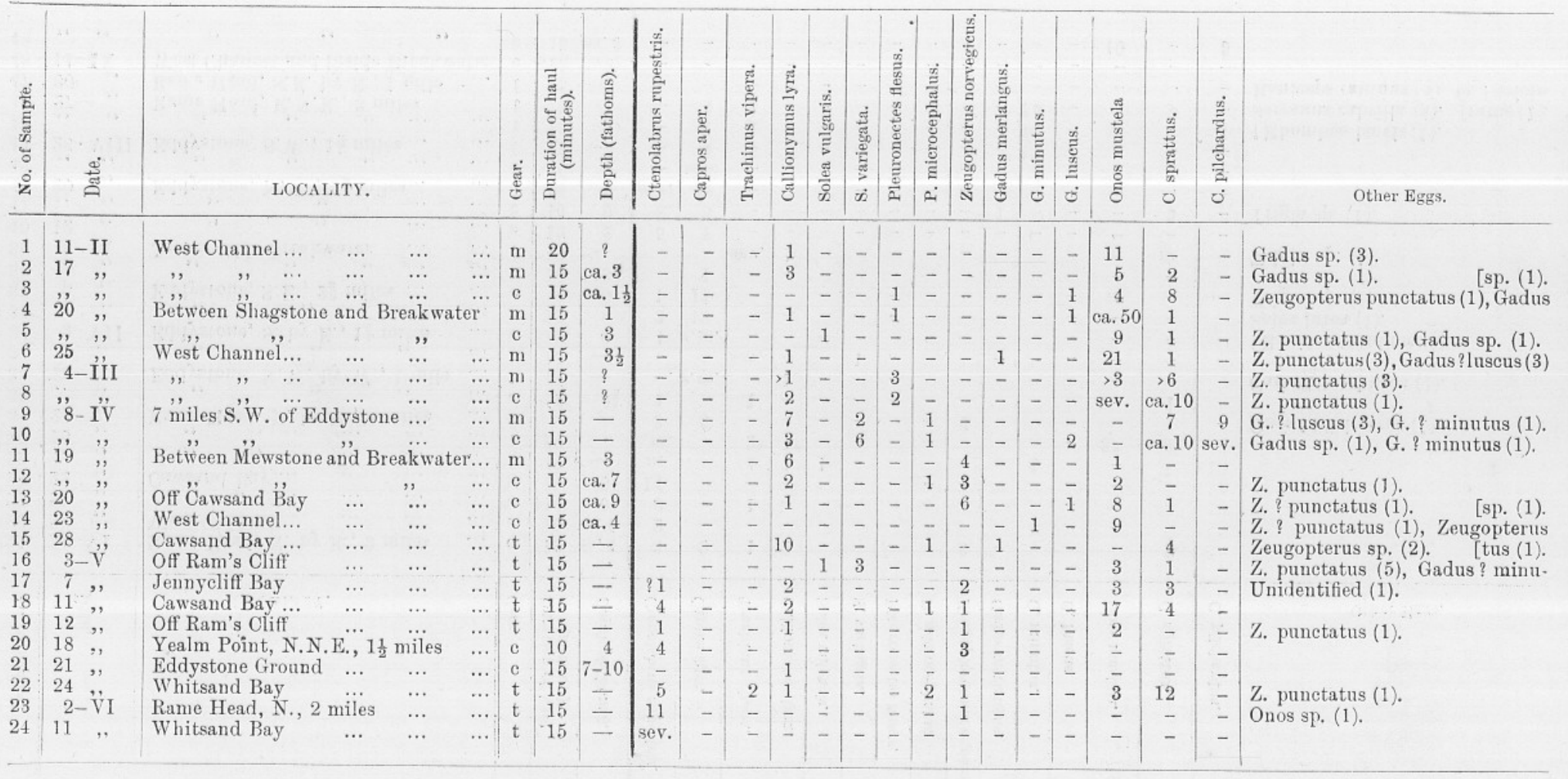




\begin{tabular}{|c|c|c|c|c|c|c|c|c|c|c|c|c|c|c|c|c|c|c|c|c|c|c|}
\hline 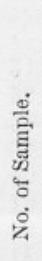 & झू & LOCALITY. & & छึँ & 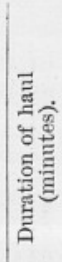 & 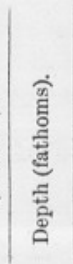 & 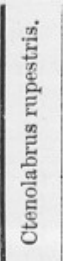 & 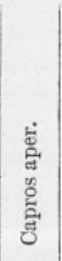 & 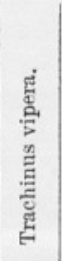 & 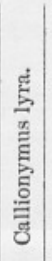 & 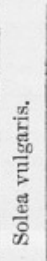 & 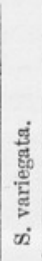 & 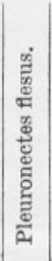 & 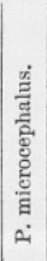 & 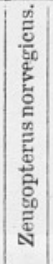 & 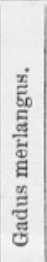 & 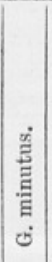 & 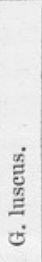 & 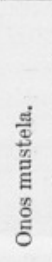 & 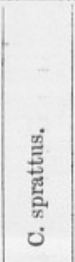 & 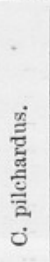 & Other Eggs. \\
\hline 25 & $14-V I$ & Rame Head, N. by E., 2 miles & $\ldots$ & c & 15 & ca. 4 & 3 & 2 & 1 & 2 & - & - & -1 & - & 3 & - & - & - & - & 2 & - & \\
\hline 26 & 21, & West Channel... $\quad \ldots \quad \ldots$ & $\cdots$ & c & 10 & ca. 4 & 2 & - & - & - & - & - & - & - & - & - & - & - & - & - & - & \\
\hline 27 & 21, & $, \quad, \quad, \quad \ldots$ & $\ldots$ & c & $? 10$ & 0 & 6 & - & 1 & - & - & - & - & - & - & - & - & - & - & 3 & - & \\
\hline 28 & 22, & Cawsand Bay ... & $\ldots$ & c & 10 & 0 & 14 & - & - & - & - & - & - & - & - & - & - & - & - & - & - & \\
\hline 29 &,, & $, \quad, \quad, \quad \ldots$ & ... & $\mathrm{t}$ & 10 & - & $\mathrm{m}$ & - & 4 & 1 & 1 & - & - & - & - & - & 1 & - & - & - & - & \\
\hline 30 & 25, & ", $\quad, \quad \cdots \quad \ldots \quad \ldots$ & $\ldots$ & $\mathrm{t}$ & 20 & 一 & v.m. & - & $2^{*}$ & $1^{*}$ & - & - & - & - & - & - & - & - & $3^{*}$ & v.m. & - & \\
\hline 31 & 28, & Rame Head, N. by E., 3 miles & $\ldots$ & c & $?$ & - & 3 & 5 & - & - & - & - & - & - & 6 & - & - & - & - & 1 & - & Onos ? tricirratus (1). \\
\hline 32 & , ", & ," & ... & $\mathrm{c}$ & 15 & $3 \frac{1}{2}$ & 4 & - & 1 & - & - & - & - & - & - & - & -1 & - & - & 1 & - & \\
\hline 33 & 29, & Eddystone, N.W. by W., 1 mile . & ... & $\mathrm{t}$ & 15 & - & - & v.m. & - & 1 & - & - & - & - & - & - & - & - & - & - & - & Caranx trachurus (1). \\
\hline $\begin{array}{l}34 \\
35\end{array}$ & "--V̈II & Eddystone, S. by"E., $1 \frac{1}{4}$ miles & $\cdots$ & $\begin{array}{l}\mathrm{t} \\
\mathrm{c}\end{array}$ & $\begin{array}{l}15 \\
12\end{array}$ & $\overline{0}$ & $\overline{4}$ & v. & sev. & $\overline{-}$ & - & 1 & - & - & - & $\overline{-}$ & $\overline{-}$ & $\overline{-}$ & - & $\overline{-}$ & -1 & \\
\hline 36 & ,, , , & & … & c & 12 & 4 & 3 & 18 & - & - & - & - & - & - & - & - & - & - & - & $\overline{-}$ & - & Solea lutea (1). \\
\hline 37 & 5, & Eddystone, S.E.," $2 \frac{3}{4}$ miles ".. & $\cdots$ & c & 10 & 0 & 1 & 11 & - & - & - & - & - & - & - & - & - & - & - & - & - & Trigla sp. (1). \\
\hline 38 & $"$, & ", $\quad, \quad, \quad \ldots$ & ... & c & 10 & 3 & - & 1 & - & - & - & - & - & - & - & - & - & - & - & - & - & \\
\hline $\begin{array}{l}39 \\
40\end{array}$ & $\begin{array}{r}8 \\
12\end{array}$ & Just outside Breakwater $\quad \ldots$ & $\cdots$ & $\mathrm{t}$ & 10 & - & $\bar{z}$ & - & sev. & 1 & - & - & - & - & - & - & -1 & - & - & $\mathrm{m}$ & - & Trigla sp. (1). \\
\hline $\begin{array}{l}40 \\
41\end{array}$ & 12 , , & $", \quad \cdots$ & $\cdots$ & c & 12 & $\begin{array}{l}2 \\
0\end{array}$ & $\begin{array}{l}5 \\
8\end{array}$ & $\begin{array}{l}1 \\
3\end{array}$ & $\overline{-}$ & - & - & $\overline{-}$ & - & - & - & $\overline{1}$ & - & - & - & $\overline{2}$ & - & \\
\hline 42 & $2{ }^{20}$, & Eddystone, N.W.," $1 \frac{1}{2}$ miles... & $\begin{array}{l}\cdots \\
\cdots\end{array}$ & $\begin{array}{l}\mathrm{c} \\
\mathrm{c}\end{array}$ & 15 & 0 & sev. & $\mathrm{m}$ & - & - & - & - & - & - & - & - & - & - & - & - & 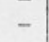 & rigla sp. (1). \\
\hline 43 & & & & c & 15 & 2 & - & sev. & - & - & - & - & -1 & - & - & - & - & - & - & - & - & \\
\hline 44 & 26 -VIII & Eddystone, S.W., $1 \frac{1}{2}$ miles ... & $\cdots$ & $\mathrm{t}$ & 15 & - & - & 4 & - & - & - & - & - & - & - & - & ?1 & - & - & - & & \\
\hline 45 &,,$\quad$, & "'ר ," & $\cdots$ & $\mathrm{t}$ & 15 & - & - & 1 & 1 & - & - & 3 & - & - & - & - & $? 1$ & - & $\overline{0}$ & - & 1 & ? Rhombus laevis (1). \\
\hline 46 & $27 \quad$, & Rame Head, E.N.E., 3 miles & $\cdots$ & t & 15 & - & - & 4 & 1 & $\overline{3}$ & - & - & - & - & - & - & $? 6$ & - & 3 & - & 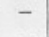 & Serranus cabrilla (4). [ratus (1). \\
\hline $\begin{array}{l}47 \\
48\end{array}$ & $30-14$ & $\begin{array}{l}\text { Rame Head, S.E. by E., } 1 \text { mile } \\
\text { West Channel and inside Breakwat }\end{array}$ & & t & $\begin{array}{r}15 \\
? 15\end{array}$ & $\overline{>3}$ & 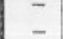 & - & $\overline{-}$ & ${ }_{-}^{3}$ & $\overline{-}$ & $\overline{-}$ & $\overline{-}$ & - & - & $\overline{-}$ & $\overline{-}$ & $\overline{-}$ & - & $\overline{-}$ & - & \\
\hline 49 & , , , & ," ,, , & & $\mathrm{c}$ & 15 & ca. 3 & - & - & - & - & - & - & - & - & - & - & - & - & 10 & - & 3 & \\
\hline
\end{tabular}

Symbols used : - Under "Gear," $m=$ medium tow-net, $c=$ coarse tow-net, $\mathrm{t}=$ young-fish trawl.

In numbers columns, sev. $=$ several, $\mathrm{m}=$ many, $\mathrm{v} . \mathrm{m} .=$ very many.

* This number only observed. Probably more present in catch. 


\section{PELAGIC EGGS.}

Ctenolabrus rupestris, L. Gold-sinny or Rock-wrasse.

Hout (11a), p. 465, Figs. 23, 24, 28-30.

Heincke u. Ehrenbaum (10), p. 266, Fig.17a-d.

THIS species afforded the most numerous of the pelagic eggs taken during the months of May, June, and July. Belonging to a littoral species it was taken for the most part in near-shore tow-nettings, and was practically absent from the offshore Eddystone Grounds; but there was one notable exception to this on July 20th, when several were taken one and a half miles south-east of the Eddystone. The egg, which is easily recognized by its small size, clear homogeneous yolk devoid of an oil-globule, small perivitelline space, and embryo with slender body and uniformly distributed pigment, has been described by Holt (op. cit.) from the south-west coast of Ireland and from the Gulf of Marseilles, and by Heincke and Ehrenbaum from Heligoland. The size of the egg is liable to much variation. The diameters recorded for the North Sea are 0.72 to $0.94 \mathrm{~mm}$., for the Mediterranean 0.70 to $0.83 \mathrm{~mm}$., and for the Irish coast $0.835 \mathrm{~mm}$. The diameter of my eggs ranged from 0.78 to $0.90 \mathrm{~mm}$., averaging 878 in May, 839 in June, and 822 in July. The first specimen was taken on the 7 th of May, the last on the 20th of July. The newly hatched larva has a total length of $2.16 \mathrm{~mm}$., the distance from snout to anus being $1 \cdot 22 \mathrm{~mm}$.

The post-larval stages have been taken in theyoung-fish trawlfrom late June onward, but they do not appear in that relative abundance which one might expect from the commonness of the ova. This is probably due to the fact that they early seek the environment of inshore rocks, which is the habitat of the adult. Holt (11d, p. 125) speaks of young examples being common on the zostera beds of Cawsand Bay and the Yealm estuary, but judging from his later publication of a drawing of a young wrasse taken at Fowey (Marseilles, 1899), and erroneously identified as $C$. rupestris, it is probable that at this time he was confusing this species with another wrasse, probably $L$. maculatus, the young of which are more commonly met with off the shores of this neighbourhood in summer. The later post-larval stages, like the early larva, are characterized by their lack of black pigment, which is limited to a large spot at the base of the posterior end of the anal fin and at the base of the caudal fin, and for the rest a little in the peritoneum, on the head and on the throat. 


\section{Serranus cabrilla, L. The Gaper.}

Raffaele (20), p. 19, Tav. I, Fig. 5, Tav. II, Figs. 1 and 3. Holt (11f), p. 11, Pl. IV, Figs. 33-40.

Four eggs with homogeneous yolk and single oil-globule were taken on August 27th and six on August 30th, in each case in plankton caught by the young-fish trawl in Whitsand Bay. In both cases the eggs soon developed unhealthy symptoms, and the characters of the embryo and larva must be considered with this condition borne in mind. The diameter of the eggs ranged from $0.92 \mathrm{~mm}$. to $0.97 \mathrm{~mm}$. and the size of the oil-globule from 0.14 to $0.15 \mathrm{~mm}$. Before the formation of the embryo the surface of the yolk presents a roughened appearance, which may be due to a slight granulation in the periblastic region (cf. Holt, op. cit., p. 12). Just before the outgrowth of the free caudal region a few round, pale yellow chromatophores have appeared along the sides of the embyro, and smaller, somewhat inconspicuous dark stellate chromatophores are fairly uniformly distributed all over the body. As development proceeds the pigment spots increase in size, single yellow chromatophores by the anus and in the mid-post-anal region being well marked. There is a little pigment of each colour over the oil-globule, but none on the yolk-sac. The hatched-out larvae were moribund in every case. The length of the newly hatched larvae (Fig. 13) varied from 1.84 to $2.30 \mathrm{~mm}$. The largest and most whole specimen measured $1.00 \mathrm{~mm}$. from the snout to the posterior edge of the yolk-sac, and $1.26 \mathrm{~mm}$. from snout to anus. The post-anal length of $1.04 \mathrm{~mm}$. should have a trifle added to it to allow for the slight shrinkage which had taken place. The pigment has a very characteristic distribution, but varies somewhat in the size and number of the chromatophores. Black pigment is confined to the dorsal (anteriorly it may be dorso-lateral) region of the head and trunk, extending as a dorsal line to the caudal extremity. The yellow, which by transmitted light shows a greenish tint, is confined on the body itself to a few rather widely separated chromatophores of large size. In an average case there are one on the head; one behind the otic region; two in the pre-anal dorsal line; two lateral spots at the level of the posterior edge of the yolk-sac; one very large one over the anus and at the mid-post-anal point in the dorsal and ventral contours. Ramifications extend into the unpaired fins in the two latter cases. All the larvae observed showed one large dorsal mid-post-anal chromatophore, but the corresponding ventral pigment may consist of as many as four chromatophores. In the dorsal fin 
there is a row of four to six large chromatophores, which usually exhibit upwardly and outwardly radiating outgrowths. The most posterior of the series is a little behind the dorsal chromatophore of the caudal region. There may be corresponding pigmentation in the anal fin, but it is not so extensive, from two to four chromatophores being the usual occurrence. The pre-anal fin may have a spot of yellow pigment near its margin, and invariably there is a small patch in its antero-dorsal angle, where the contours of yolk-sac and intestine converge. There is no pigment on the yolk-sac, but over the oilglobule there are one or two chromatophores of each colour.

Normally the yolk-sac is somewhat elongated and bears the oilglobule at its anterior end, but the position of the oil-globule shows some variation, and in two cases was only just within the anterior hemisphere.

The general form of the larva resembles that of Holt's Fig. 33 (op. cit.), the characteristic features apart from pigmentation being the ovoid yolk-sac with anteriorly placed oil-globule and the broad preanal fin membrane.

My late embryos and larvae all showed a marked tuberculated epidermis, which was doubtless a pathological condition, and may be regarded as diagnostically unimportant.

On referring to previous observations by Raffaele and Holt of Mediterranean species, one finds conspicuous characteristic features which are common to all the above and to my Channel specimens, but there are also puzzling variations which, in the case of the Gulf of Marseilles specimens, do not seem to be altogether explicable as being the result of partial observations of more than one species. Raffaele (op. cit., p. 19) deals with the eggs of three species, which I give below with the dimensions :-

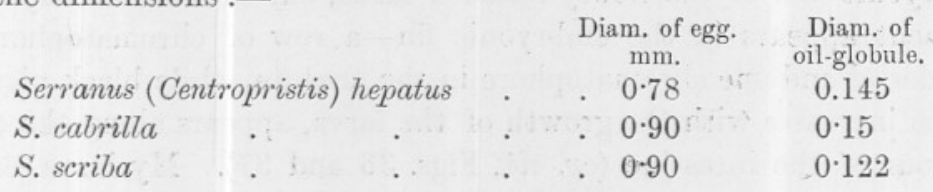

He figures the larvae of $S$. scriba and S. cabrilla (Tav. 2, Figs. 1-4), but does not give larval dimensions nor any further indication as to the specific pigmentation than can be derived from the uncoloured drawings.

In size my eggs agree most with his $S$. cabrilla, although slightly larger. Raffaele's newly hatched S. cabrilla larva has the oil-globule, centrally situated, while his $S$. hepatus shows it anteriorly situated. The former has large mid-post-anal dorsal and ventral chromatophores: 
In the unpaired fins of the newly hatched larva there is no pigment, but a four to five days' old larva shows two large chromatophores on the dorsal and anal fins.

Holt (op. cit., p. 11) examined several Serranoid eggs from the Gulf of Marseilles and found among them unusual variability. The diameter varied from 0.72 to $0.89 \mathrm{~mm}$. (for the most part lying between 0.78 and $0.84 \mathrm{~mm}$.), and the oil-globule from 0.14 to $0.16 \mathrm{~mm}$. He found that the embryonic pigment, which first appeared before the outgrowth of the caudal rudiment (the black generally, but not always, preceding the yellow), showed considerable variation, while there appeared to be no constant relation between the variations. As to the nature of the yellow pigment (often greenish yellow by transmitted light, and very pale by reflected light) Holt's records (as well as Raffaele's) agree with my observations. Both black and yellow chromatophores are shown as a rule over the oil-globule, but never over the rest of the yolk-sac. In all Holt's observations of the newly hatched larvae the oil-globule was anterior, the pre-anal part of the body slightly longer than the post-anal, the multicolumnar notochord had its vacuoles arranged fairly regularly in two series, dorsal and ventral. Pigment was disposed along the whole length of the dorsum, and was sometimes present on the sides and intestinal region. The yellow chromatophores followed the contour of the dorsum, and post-anally there were only two spots, a dorsal and a ventral, generally well defined, marking the centre of the post-anal region. The pigment on the head varied. There was always a spot at the angle formed by the intestine and the dorso-posterior profile of the yolk-sac, and also in the region of the urocyst, and sometimes others over the intestine. It is to be noted that Holt never observed any pigment in the embryonic fins of the newly hatched larva, but after three days black pigment appears in the embryonic fin-a row of chromatophores in the dorsal and one chromatophore in the anal fin, while black pigment, which increases with the growth of the larva, appears along the dorsal contour of the intestine (op. cit., Figs. 36 and 37). My larva, on the other hand, shows soon after hatching a row of yellow chromatophores in the dorsal fin. Otherwise it agrees with the youngest larval stages which Holt represents in Figs. 33, 34, and 35, and refers to Serranus (hepatus?). It is possible that the early appearance of yellow pigment in the dorsal fin is a characteristic of $S$. cabrilla, which distinguishes it from $S$. hepatus, the species probably observed by Holt. However, a still later stage observed by him ("alévin âgé de quelques jours"), of apparently the same species, does show large yellow chromatophores associated with the relatively diminutive black ones in the embryonic 
fins, and also differs from the other larvae in having the black pigment of the body predominantly ventral instead of dorsal. A still further distinct variation is shown in an older stage with the yolk almost absorbed and the mouth open (but only $2.06 \mathrm{~mm}$. long), which has much yellow and no black in the embryonic fin (op. cit., Fig. 40).

With the material at his disposal and the small assistance derived from Raffaele's incomplete observations, Holt was unable to come to any definite interpretation of these unusual and irregular variations of larval pigment; and the still further difference displayed by my larvae does not add light to the problem. Holt referred them, or at least some of them, to $S$. hepatus as the most probable parent, on account of their smaller size as compared with Raffaele's, and because of the greater abundance of this species in the area from which his eggs were taken. He also admits the possibility of some $S$. cabrilla eggs being present among his specimens.

As to the specific identity of my eggs I have little doubt in ascribing them to $S$. cabrilla, which is a constant, though not common, inhabitant of Channel waters. As far as can be judged from Raffaele's incomplete records, the egg and larva agree with his S. cabrilla from the Bay of Naples, except that his figures show no pigment in the embryonic fin of the newly hatched larva, but only at a later stage. The dimensions of the egg and oil-globule show practical agreement. The date of the occurrence of the eggs agrees with Day's record of the spawning season of $S$. cabrilla. The only other member of the genus known to British waters is $S$. gigas, Cuv. and Val, mentioned by Day as an occasional and accidental visitor, who also states that "in warmer climates it deposits its ova in shallow water." I do not know of any description of the ova of this species. It does not seem likely, however, that it would spawn successfully here.

Caranx trachurus, L. Scad or Horse Mackerel.

HoLt* (11b), p. 9 ; (11d), pp. 116-20 and 340.

(11f), pp. 27-31, Figs. 53-63.

Cand (3b), pp. 63-71. Pl. V, Figs. 1-6.

Heincke and Ehrenbaum (10), p. 277, Figs. 28-31.

Ehrenbaum (5c), p. 234.

Although this species was exceedingly common off the coast in the early summer months only one egg was taken. This occurred in the catch of the young-fish trawl taken near the Eddystone on 29th June. It was not closely observed till the following day, when the larva had

* See also North Sea Investigations, VI. "The Reproduction of Caranx trachurus," Journ. M.B.A., Vol. IlI, N.S., pp. 190-4 (1893-5). 
hatched out, but in an unhealthy condition and with the tail much bent. It was recognized by the larval pigmentation and by the totally segmented yolk, which bore anteriorly an oil-globule of $0.24 \mathrm{~mm}$. diameter. The black and yellow pigment had a similar distribution to that in Holt's and Ehrenbaum's figures, but was not so strongly marked. On account of the deformity of the tail it was impossible to ascertain the total length. It measured $0.98 \mathrm{~mm}$. to the posterior contour of the yolk-sac. Post-larval stages have occasionally appeared in the catches of the young-fish trawl in July and August. It would appear, therefore, that the fish spawns out in deep water, the drift of the eggs and larvae towards the coast requiring some little time. . It will be noticed that my solitary egg was at the last stage of embryonic development when taken. Its unhealthiness also is in keeping with the general rule that the more the habitat of the species lies in the open sea the greater the difficulty experienced in rearing the larva in the laboratory. In spite of the abundance of scad at this time in these waters, all those I was able to examine were immature, so that I inferred that the older and spawning fishes did not approach the coasts so closely. Against this, however, it must be stated that as the result of his investigations in the North Sea, Ehrenbaum (op. cit., p. 235) finds that Caranx trachurus favours as spawning places the shallow coastal areas from 10 to $25 \mathrm{~m}$. depth, while outside the $30 \mathrm{~m}$. line only few eggs were found.

Previous records of the occurrence of this egg in the Plymouth neighbourhood are confined to the observations of Holt (11d, p. 116), who obtained four specimens in July, 1897. The diameter of the egg was 0.81 to 0.93 , and the oil-globule 0.22 to $0.23 \mathrm{~mm}$.

\section{Capros aper, Lacep. Boar-fish or Cuckoo.}

The pelagic eggs of this species first appeared in tow-nettings taken on 14th June, and from the end of that month to the end of August our samples from the deeper water contained a well-marked preponderance of these eggs, which were especially numerous at the beginning of July in the neighbourhood of the Eddystone. The embryonic characters were first described by Cunningham (4a, p. 10), who artificially fertilized ova in August, 1897, and Holt has published descriptions and drawings of the larval stages (11f, p. 26, Pl. V, Figs. 43-8). Pelagic eggs taken by him varied from 0.93 to $1.01 \mathrm{~mm}$. in diameter (chiefly 97 to $\cdot 99$ ), and contained an oil-globule of 0.15 to $0.165 \mathrm{~mm}$. diameter. The average dimensions of my ova were:diameter of egg, $0.946 \mathrm{~mm}$.; diameter of oil-globule, $0.156 \mathrm{~mm}$.; and the range of size was from 0.90 to $0.98 \mathrm{~mm}$. for egg, and from 0.145 to 
$0.17 \mathrm{~mm}$. for oil-globule, which was frequently of a yellowish tint. The species may be readily recognized towards the end of embryonic development by the characteristic yellow and black pigmentation. The yolk is homogeneous, the oil-globule of a yellowish tint, and the capsule marked with fine corrugations. At about the time of the outgrowth of the caudal rudiment black chromatophores appear on the head and in a line on either side of the body. A rather large Küpfer's vesicle is visible at this stage. Yellow pigment appears soon afterwards. One larva soon after hatching measured $1.40 \mathrm{~mm}$. from snout to anus, and about $2.46 \mathrm{~mm}$. in total length. Another had a total length of $2.02 \mathrm{~mm}$., the distance from snout to end of yolk-sac being $1.08 \mathrm{~mm}$. Black and yellow pigment occurs in rather large, stellate or dendritic chromatophores on the head and along the sides of the body. At about the level of the anus and in the mid-post-anal region there is a tendency for it to be more concentrated. The embryonic fins and the posterior extremity of the trunk are unpigmented.

In spite of the abundance of pelagic ova not a single larval or postlarval specimen occurred in our young-fish trawl collections. The young fish appear to seek early the deeper parts of the Channel. The only specimen recorded up to the present is one of $15 \frac{1}{4} \mathrm{~mm}$. length, taken in September, 1906, by the Danish research steamer Thor, to the west of the Channel Islands (21d, p. 5).

\section{Trachinus vipera, Cuv.}

This conspicuous and very easily identified egg occurred frequently though not abundantly in our samples from the latter part of May to the end of August. The many bright yellowish-green oil-globules and the richly pigmented embryo and yolk-sac render it a conspicuous object in the tow-nettings. The diameter lay between $1.28 \mathrm{~mm}$. (in May and June) and $1.1 \mathrm{~mm}$. at the end of August. Post-larval stages were frequently taken from the end of June throughout the summer.

\section{Trigla. The Gurnards.}

There are five species of Trigla occurring in the waters off Plymouth, and the specific identification of their pelagic eggs, which are similar in character and show considerable overlapping in dimensions, is a matter of great difficulty and often an impossibility. The only circumstances which ensure certainty of determination are when the spawning fish are captured in quantity at about the same time and in the same area as the eggs, so that an extensive comparison can be made between the planktonic eggs and those taken from the ripe fish. 
Such, for example, were the conditions under which Holt (11b, p. 31) was enabled to identify the eggs of $T$. cuculus taken in April and May off the west coast of Ireland, and similarly Ehrenbaum (5c, p. 248) has made extensive measurements of planktonic and artificially fertilized ova of T.gurnardus in the North Sea, the main purpose in the latter case being to distinguish between grey gurnard eggs and those of the mackerel, which may to a certain extent coincide in diameter and size of oil-globule.

The following table shows the dimensions of artificially fertilized Trigla ova from four species which have previously been described by various observers :-

\begin{tabular}{|c|c|c|c|c|}
\hline Species. & Observer and locality. & Month. & Diameter. & $\begin{array}{l}\text { Size of oil- } \\
\text { globule. }\end{array}$ \\
\hline $\begin{array}{l}\text { T. gurnardus } \\
\text {,", } \\
\text { T. hiruindo } \\
\text {,", } \\
\text { T. cuculus } \\
\text { T. lineata }\end{array}$ & $\begin{array}{l}\text { Cunningham (Plymouth) } \\
\text { Holt (west coast of Ireland) } \\
\text { Ehrenbaum (Helgoland) } \\
\text { Canu (Boulogne)" } \\
\text { Ehrenbaum (Helgoland) } \\
\text { Cunningham (Plymouth) } \\
\text { Holt (west coast of Ireland) } \\
\text { Holt (Plymouth) }\end{array}$ & $\begin{array}{l}\text { April-May } \\
\text { June } \\
\text { July } \\
\text { May-July } \\
\text { July } \\
\text { August } \\
\text { April-May } \\
\text { May } \\
\text { July }\end{array}$ & $\begin{array}{c}1 \cdot 45 \\
1 \cdot 43-1 \cdot 55 \\
1 \cdot 256-1 \cdot 258 \\
1 \cdot 163-1 \cdot 446 \\
1 \cdot 5-1 \cdot 7 \\
1 \cdot 193 \\
1 \cdot 1-1 \cdot 352 \\
1 \cdot 45 \\
1 \cdot 47-1 \cdot 61 \\
1 \cdot 29-1 \cdot 33\end{array}$ & $\begin{array}{l}0.30 \\
0 \cdot 28-0 \cdot 33 \\
0 \cdot 25 \\
0 \cdot 25 \\
0 \cdot 27-0.29 \\
0 \cdot 24 \\
0 \cdot 22 \\
0 \cdot 30 \\
0 \cdot 28-0.33 \\
0 \cdot 24\end{array}$ \\
\hline
\end{tabular}

Besides the above four species, Trigla lyra, L., commonly known as the Piper, occurs off Plymouth in appreciable quantities, but its ova have never been described. A further difficulty is introduced by the great variation which is shown by the eggs of the same species observed in different regions and at different times. In spite of this, however, Canu (3b, p. 72) has stated that, as regards the eastern part of the Channel, the eggs of T. hirundo exceed in diameter those of all other members of the genus, but he does not give any actual observations to support this statement.

Out of my own collection, during the summer of 1909 , I can only refer three eggs with absolute certainty to the Trigla genus. As to their specific identity I can say nothing, except that $T$. lineata appeared to be the most common species off Plymouth at the time (July) and may possibly have been the parent fish. There are few descriptions of gurnard eggs and larvae on record at present, so it may serve a useful purpose for future comparison if I briefly give here my own observations. On the 5th of July an egg was taken about $2 \frac{3}{4}$ miles north-west of the Eddystone. Its diameter was $1.4 \mathrm{~mm}$., and it contained an oilglobule of $0.22 \mathrm{~mm}$. Observed on the same day, the blastodisc had almost half enveloped the yolk. Next day the embryo had formed; 
the myotomes were very distinct, and faint dark pigment was just appearing. Less than twenty-four hours after this a short caudal rudiment had appeared, and the body was beset with both black and yellow pigment cells. In the caudal region yellow predominated, covering the dorsal surface almost entirely, while of black there were only a few round chromatophores. Over the yolk-sac there were many black and yellow chromatophores stellate and cruciform in shape, and the pellicle of the oil-globule was covered with large black dendritic chromatophores, each with many ramifying rays. The rudimentary pectoral fins occurred as relatively large flap-like outgrowths. On the fourth day, when the embryo had wholly surrounded the yolk, yellow pigment had increased in intensity, especially in the post-anal part, and had appeared on the pectoral fins. Black dendritic and pectinate pigment patches, together with yellow pigment, were visible on the embryonic fin membrane. The otocysts were relatively small, and situated so that the distance from the posterior edge of the eye to the posterior edge of the otocyst was equal to the diameter of the eye. The oil-globule had shrunk to a diameter of $0.20 \mathrm{~mm}$. The egg died before hatching.

On the 8th July another egg of $1.28 \mathrm{~mm}$. diameter and oil-globule $0.215 \mathrm{~mm}$. was taken a short distance south of the Breakwater. The embryonic character as to pigmentation, etc., was quite similar to the above-mentioned, and fortunately this proved to be more healthy. On the 12 th the larva was found to have hatched out and was then probably over twenty-four hours old, the yolk being partially absorbed. Its length was $4.5 \mathrm{~mm}$, the distance from snout to anus being $1.7 \mathrm{~mm}$. At this stage it has a general resemblance to a Zeugopterus larva, but the body is less elongate, the anus relatively nearer to the yolk-sac, and the well-developed and richly pigmented pectoral fins especially characterize it as Trigla. There is no well-defined "snout" and the frontal region is peculiarly square. The bean-shaped otocysts, with two very small otoliths, are placed immediately behind the eye. The oil-globule is situated at the posterior end of the yolk-sac, between which and the anus there is a short but deep pre-anal fin. The rectum lies at right angles to the longitudinal axis. Dorsal to the gut above the middle of the yolk-sac is a conspicuous spherical swim-bladder. The pigment is bright canary-yellow and black. The whole of the head, except the eyes, is diffusely covered with yellow. In the eye black is beginning to appear. A continuous dorsal series of rather diffuse yellow chromatophores runs back from the head to a point about $1.1 \mathrm{~mm}$. from the posterior extremity, beyond which both marginal fins and body are quite unpigmented. A similar but less 
intense line runs along the ventral contour of the trunk. Over the surface of gut and yolk-sac is a diffuse covering of pale yellow and faint dendritic black markings. The pectoral fins are intensely yellow, with black etching-like markings round the margin in radial arrangement. On the unpaired fins there are large dendritic black and yellow chromatophores, distally distributed for the most part. In the anal fin all the pigment is marginal, while in both dorsal and anal there are fine, black, pectinate markings along the edge of the fin, similar to what is seen in Zeugopterus norvegicus.

A third Trigla egg of $1: 34 \mathrm{~mm}$. diameter was taken on 12th July, $1 \frac{1}{2}$ miles south of Rame Head. The embryo had formed, but the oil was still in two globules of 0.23 and $0.13 \mathrm{~mm}$. diameter, which joined to make a single globule next day. On the fourth day the larva hatched out. Its total length is now $4.45 \mathrm{~mm}$., the pre-anal length being $1.75 \mathrm{~mm}$. In general form and pigmentation it resembles the larva above described, which was observed at a somewhat older stage. It differs slightly from that, however, in having less black pigment in the dorsal and anal fins, nor is the marginal pigment of the pectoral fin as strongly marked. Next day its length has increased to $4.74 \mathrm{~mm}$. and the yolk is almost absorbed. The pectoral fins are much larger and now show the marginal fringe of black very plainly. The mouth has become distinctly enlarged and already has the characteristic gurnard form. Two days later, on the 19th, the larva, with but a very small amount of yolk left unabsorbed, has lost the brilliant yellow colouring of the younger stages. It is still fairly well marked, although diffuse, over the dorsal surface of the head and trunk, but less distinct over operculum, along the sides of the pre-anal part of the trunk and on the pectoral fins. In the unpaired fins the marginal pigment is much reduced. Black pigment has increased, especially on the pectoral fins, which it now covers from margin to basal part, but the marginal fringe is still the most dense. Dendritic chromatophores occur at intervals along the margin of the dorsal fin, but are very sparse on the anal fin except in the hypural area, where there is a rich supply arising at the ventral edge of the tail and ramifying over the fin membrane. On the corresponding dorsal side there is a faint indication of the same thing. Fine dendritic chromatophores occur on the body, being most concentrated along the dorsal contour of the gut and along the ventrolateral part of the post-anal region. Large otocysts containing relatively small otoliths are situated immediately behind the eyes. The large fan-shaped and heavily pigmented pectoral fins, and the head which is conspicuous from its well-developed jaws and operculum, give this larva a very characteristic appearance. 


\section{Callionymus lyra. Dragonet.}

Although most abundant in the months of March and April and of rare occurrence during the summer, the presence of these eggs in the plankton has been recorded from 11th February to 30th August, the first and last occasion of the year on which searches for fish-ova were definitely made. The diameter of the egg varied from 0.70 to $0.91 \mathrm{~mm}$., the average for February to April being 0.796, May to June 0.803, July and August, 0.74. Post-larval stages from about 3.5 to $10 \mathrm{~mm}$. were exceedingly common from April to August in the youngfish trawl material.

\section{Pleuronectes.}

The paucity of the eggs of this genus in our samples is greatly due to the fact that, by the time the systematic collection of samples was commenced, the spawning season of the species occurring off Plymouth was more or less over. Moreover, the regions favoured as spawning localities by the plaice ( $P$. platessa), dab $(P$. limanda), "merry-sole" ( $P$. microcephalus) are in the deep water at some distance from land, to which there is a regular off-shore migration for the colder months of the year, in which period most of the spawning of these species occurs. The flounder ( $P$. flesus) is an exception. Seven eggs of this species were taken in four "hauls" in the Sound between 17th February and 4th March, and post-larvae were common in May. No plaice eggs were taken, the spawning being practically over by the end of January. Previously published observations of the occurrence of plaice eggs are confined to the records of the obtaining of one egg on 12th February and 7th March, 1902, by F. Balfour Browne (2, pp. 607 and 609). I myself have obtained no specimen of the pelagic post-larva, nor is there any record of such having been taken at Plymouth, due, I believe, to their off-shore spawning region. However, I hope to have more to say as to the distribution of the young Pleuronectidae in a later paper.

$P$. microcephalus eggs have been most frequently met with, but on five out of six occasions when this egg has appeared in my plankton samples, it has been only a single specimen. The first specimen was taken on 8th April and the last on 24th May, but before that period no off-shore tow-nettings had been collected. The diameter of the egg varied from 1.30 to $1.38 \mathrm{~mm}$. A newly hatched larva measured $4.84 \mathrm{~mm}$. Only one post-larva was taken-in July, off the Eddystone. In previous years, however, this stage has been more abundantly represented in our samples.

No eggs of $P$. limanda were taken, and on two occasions only (in

NEW SERIES. -VOL. IX. NO. 1. OCTOBER, 1910. 
May and June) were post-larvae obtained. There is one record only of the occurrence of the egg of the dab in the Plymouth neighbourhood, viz. on 14th April, 1902, south of the Mewstone (2, p. 613), but this, again, is probably due to the dearth of samples from the off-shore areas.

\section{Solea vulgaris, Quensel. The Common Sole.}

The only remark to be made concerning the occurrence of this wellknown and easily recognized egg is as to its rareness in our samples, only three specimens having come into our hands through the whole season, viz. one in February at the eastern entrance to the Sound, one in May in the Sound, and one in June in Cawsand Bay. This was probably due to the fact that no samples were collected during practically the whole of March. This month, according to Cunningham (4b, p. 117), represents the height of the spawning season, which extends from the middle of February to the end of April. A further cause is the fewness of our samples during this period from the deep off-shore waters where the spawning fishes appear to occur in greater numbers. Pelagic young fish have likewise been very few, less than ten being taken throughout the season from April to the end of August.

Solea lutea, Bonaparte. Solenette.

HoLt (11a), pp. 460-4, Figs. 9, 10, 46-52.

(11f), pp. 87-9.

Ehrenbaum (5a), pp. 312-17, Figs. 31-5.

One specimen of the egg of this species was taken in a tow-net at a depth of about 4 fathoms $1 \frac{1}{4}$ miles $\mathrm{N}$. by W. of the Eddystone on 2nd July. It was not perfectly spherical, and measured 0.80 by $0.84 \mathrm{~mm}$. The yolk contained 14 oil-globules of a pale amethyst tint. On the day of capture the embryo had developed a short caudal rudiment. Dull pale yellow pigment was present on the yolk-sac and abundant on the body, and a few black chromatophores were also visible on each. On being next examined, three days later, the larva was found to have hatched out and almost absorbed the yolk. Its total length was $3.01 \mathrm{~mm}$., the distance from snout to anus being $1.03 \mathrm{~mm}$. Dull yellow pigment in large dendritic chromatophores was present on the body, head, snout, and along the margin of the unpaired fins, with the characteristic large patch at the commencement of the posterior half of the tail. There are two large patches and a smaller anterior one on the anal fin. On each well-developed pectoral fin there is a large patch of pigment, which does not appear to have been mentioned by previous observers. 
I have not found among my young-fish trawl collections this year any post-larval stages which I can with certainty ascribe to this species.

Solea variegata (Donov). Thickback.

Cunningham (4a), p. 23, Fig. 15.

(4b), p. 90 ; Pl. XVI, Fig. 6 ; Pl. XVII, Figs. 1 and 2.

HoLt (11d), p. 137.

This is the species of Solea which yielded the greatest total of eggs in our samples, fifteen altogether being taken for the season. Considering the relative abundance of the parent fish, previous records for Plymouth are surprisingly meagre. Cunningham first obtained a pelagic egg of $1.36 \mathrm{~mm}$. diameter in July, which he identified chiefly by comparison with the ovarian egg from a ripe female taken the previous May. In his treatise on the Common Sole, 1890, he figures the newly hatched and two days' old larva, the former being $2.42 \mathrm{~mm}$. in length. He describes the eggs as measuring 1.28 to $1.36 \mathrm{~mm}$. in diameter, and therefore smaller than those of the common sole. It may here be mentioned that there seems to be no evidence for Ehrenbaum's statement (5b, p. 143) that it is larger than that of $S$. vulgaris, at least as regards the Channel specimens of the latter species (cf. 7, p. 23), although observations in the North Sea (where $S$. variegata does not occur) have given a smaller diameter for the eggs of the common sole. Holt (op. cit.) records a single egg of $1.11 \mathrm{~mm}$. diameter, taken in the Hand Deeps in July, which died before being completely examined; and Balfour Browne (2, p. 615) mentions the taking of one in the West Channel on 21st April, the diameter of which was $1.44 \mathrm{~mm}$.

My earliest specimens (eight in number) were taken by tow-nets 7 miles south-west of the Eddystone on the 8th of April, but I was not able to examine them carefully until a day or two later, when most of them had hatched out. One of the eggs had a diameter of $1: 36 \mathrm{~mm}$. The yolk showed a superficial segmented layer and contained about forty oil-globules, more or less uniformly distributed below its surface. The embryo had developed a free caudal rudiment of moderate length. There were many round pale yellow or strawcoloured chromatophores and fewer small black ones on the body of the embyro and on the yolk-sac. The length of a larva, measured about one day, or possibly slightly more, after hatching, was $3.17 \mathrm{~mm}$, from the snout to the posterior edge of the yolk-sac being $1.5 \mathrm{~mm}$.

Three other eggs taken with the young-fish trawl in the Sound on the 3rd May were able to receive more attention. Their diameters 
were $1.34,1.36$, and $1.30 \mathrm{~mm}$. The first had between forty and fifty oil-globules, varying from 0.015 to as large as $0.12 \mathrm{~mm}$.; the second possessed about fifty and possibly more oil-globules of diameter from 0.015 to as large as $0.12 \mathrm{~mm}$; the third had only thirty-four oilglobules of diameter $0.024-0.12 \mathrm{~mm}$. At the commencement of the development of the caudal rudiment black and yellow pigment occurs, the former colour in rows of small chromatophores displaying stellate forms. The larva, measured during the first day after the hatching, has a total length of $2.88 \mathrm{~mm}$., the distance from snout to anus being $1: 38 \mathrm{~mm}$. The yolk-sac is very globular in shape. Yellow is the prevailing pigment, occurring in large, stellate chromatophores over the body, embryonic fins, and yolk-sac. Large, stellate, black chromatophores are also to be seen over the yolk-sac, but they are not very intense, and they are less numerous than the yellow. Black, stellate pigment spots are also distributed along the body, chiefly on the dorsal region, but at the posterior extremity is a short series of three along the ventral contour. The most conspicuous black pigment is in a series of twenty-five large, irregular, stellate or dendritic chromatophores along the margin of the dorsal fin membrane, extending from the occipital region to about $0.4 \mathrm{~mm}$. from the caudal extremity. There is a similar series along the margin of the anal fin membrane, but consisting of only six chromatophores. This specimen is practically identical with the somewhat older specimen figured by Cunningham in "A Treatise on the Common Sole," Pl. XVII, Fig. 2.

Subsequent specimens of this egg were taken on 29th June 1 mile S.E. by E. of the Eddystone (1 egg of $1.29 \mathrm{~mm}$. diameter), and on 26th August in about the same area (3 eggs, 2 of which measured 1.26 and $1.3 \mathrm{~mm}$. in diameter), in each case in the catch of the youngfish trawl. One or two post-larval stages were obtained in July and August from the deeper layers of water between Plymouth Sound and the Eddystone region.

\section{Solea lascaris, Bonaparte. Sand Sole.}

Holt (11a) (Species I), p. 457, Pl. XLIX, Fig. 26; Pl. L, Figs. 34, 35.

(11f) (? Solea lascaris), p. 84, Pl, V, Figs. 50, 51.

On 14th March, 1910, a single egg with the segmented yolk cortex typical of Soled and containing many oil-globules was taken in the townet between Plymouth Sound and the Eddystone. Examined on the 15th March, its diameter was about $1.36 \mathrm{~mm}$., and the oil-globules, which numbered more than fifty, showed a characteristic arrangement. They were not aggregated closely together in opaque clusters as in 
Solea vulgaris, nor distributed fairly regularly about the yolk as in $S$. variegata and $S$. lutea, but were arranged so that the majority of them formed a circle round the yolk outside the margin of the blastoderm, while there were also a number closely aggregated into a group at the vegetative poles.

Four days later (on the 19th) the larva was found to have hatched out (see Fig. 11) and was then probably in its first day of larval life. Its total length was $3.46 \mathrm{~mm}$. and its pre-anal length $1.4 \mathrm{~mm}$. The yolk-sac at this stage is very globular, the oil-globules being mostly in the ventral part of it. The head, body, unpaired fins and pectorals (which later become rather conspicuous), and yolk-sac are liberally sprinkled with dull, pale yellow chromatophores, from the well-marked rounded centres of which ramify dendritic outgrowths. There are black pigment spots having generally the same distribution but less numerous, especially on the yolk-sac and unpaired fins. The caudal region, where embryonic fin-rays are making their appearance, is unpigmented. Black is beginning to appear in the eyes. Two days later the yolk is reduced to about the size of the head, but still shows several oil-globules also reduced. The total length is about $3.7 \mathrm{~mm}$; from the snout to the anus about $1.52 \mathrm{~mm}$. The eyes are black with greenish tints. The midbrain is well developed and the frontal region prominent-of the typical Solea type. The mandibular region is also well developed, but the mouth is not yet open. The gut now has a ventral bend above the posterior half of the yolk-sac. The pigment is practically unchanged, except for a concentration into marginal patches along the unpaired fins-six in the anal and nine in the dorsal fin-each patch consisting of a mass of dendritic chrome-yellow, usually with a somewhat dense black spot in the centre. The pectoral fins are large, well pigmented, and generally in active movement. The following day saw a further reduction of yolk, but there was still some left. The gut has now a pronounced U-shaped bend. The mouth is apparently about to open. The pigmentation of the unpaired fins shows further concentration into patches along the extreme margin. Yellow (dull brown by transmitted light) forms the greater part of each patch. The rest of the fins and body are also well covered with dendritic and irregularshaped chromatophores. The frontal region is further developed and certainly constitutes a remarkable feature of the larva, but is nothing like Holt's drawing of his "Species I-Solea (?)" (11a, Figs. 34 and 35$)$.

On the 23rd (viz. four days after the larva was first observed) it showed signs of ill-health and the tip of the tail had become shrunken 
and crooked. There is still a portion of the yolk left, although the gut is now completely looped. The mouth is now open and conical teeth are visible in the lower jaw. The head is relatively enormous, the midbrain of considerable size and forwardly protruding. The dorsal fin membrane is very deep over the head and anterior part of the body. At this stage the specimen was killed.

A similar egg to mine was taken in July, 1890, in Clew Bay, and has been described by Holt (11a). The diameter was $1: 38 \mathrm{~mm}$., and the numerous oil-globules had a characteristic arrangement, different from that of the other known British species of Solea but resembling that exhibited in my specimen.

The resulting larva, however, was very different from mine, and was especially remarkable for its peculiar cephalic contour caused by a precephalic vesicular expansion of the dorsal fin. The very slight occurrence of black pigment and the limited distribution of the yellow chromatophores in the unpaired fin (op. cit., Pl. L, Fig. 34) constitute another and probably more important difference between that larva and mine. The same authority obtained a second egg in the Gulf of Marseilles (11f, loc. cit.) of $1.36 \mathrm{~mm}$. diameter and of similar character in regard to its numerous oil-globules, and referred to as "? Solea lascaris, Risso." He points out its similarity to Raffaele's “Sp. A " (20, p. 43, Tav. 1, Figs. 32 and 33; Tav. 3, Figs. 4-9), which, however, has a smaller egg and more black pigmentation than Holt's, in which latter character it approaches much more nearly to mine. Holt (11f, p. 86) is inclined to minimize the importance of this difference, remarking, "que le seul alevin que j'ai vu n'était pas né sous le beau soleil du midi, chose à prendre en compte lorsquon parle de coloration," and since the dorsal precephalic prominence is probably an abnormal and certainly not a constant character (Raffaele, for example, shows it in Tav. 3, Fig. 5 only, and McIntosh and Prince (16, p. 850), referring to a similar protuberance over the brain in a single specimen of Solea vulgaris, regard it as an abnormal feature), there is much probability that Holt's larva from the Irish egg is the same species as mine, the latter being the more normal form. Ehrenbaum (5b, p. 149) does refer it to Solea lascaris, suggesting that Raffaele's "Sp. A" on account of the smaller diameter of the egg may probably be Solea Kleini, Bp. 


\section{The Top-knots. (Zeugopterus.)}

I follow Petersen* in referring all three Top-knots known in the Plymouth neighbourhood to the genus Zeugopterus. Under this heading, then, we have to consider:-

Zeugopterus norvegicus, Coll. (Scophthalmus norvegicus, Gthr.)

" punctatus (Bl.) (Rhombus punctatus, Gthr.)

" unimaculatus (Risso), Day. (Phrynorhombus unimaculatus, Gthr.)

I have named them in order of the abundance of adults, so far as is known, in the neighbourhood of Plymouth Sound. Zeugopterus norvegicus occurs fairly commonly on the Rame-Eddystone ground, and I learn from fishermen that it has been taken in increased abundance of late years. The other two species are more littoral, rock-haunting fish, and therefore do not lend themselves to capture in a trawl to the extent that $Z$. norvegicus does. $Z$. punctatus is not infrequently taken on the rocks between tide-marks, and sometimes finds its way into the shrimp-trawl. Z. unimaculatus has not come into our collections in my own experience at Plymouth, and I can only state that it has been known to occur here. $\dagger$

Holt (11d, p. 128) and Balfour Browne (2, p. 600) have taken pelagic Zeugopterus eggs here in the spring months of 1897 and 1902 , but the observations have not yielded sufficient information to enable a definite conclusion to be made as to their identity. I have been more fortunate in obtaining a large number of eggs and in having at my disposal the solution of the identity of one of the species, viz. Z. norvegicus, which Ehrenbaum's work at Helgoland has rendered available (5b, p. 210).

Below I give a list of all the Zeugopterus eggs taken in my collections in 1909. In the majority of cases they were kept until the justhatched larva could be observed. It will be seen that they group themselves into two classes, those in Column I having a diameter of $0.75-0.90 \mathrm{~mm}$. and an oil-globule of $0.095-0.15 \mathrm{~mm}$., while Column II contains the larger eggs of $0.96-1.05 \mathrm{~mm}$. diameter and $0.17-0.195 \mathrm{~mm}$. diameter of oil-globule.

* Report of the Danish Biological Station, XII, 1902-3, p. 26.

+ A specimen of $Z$. unimaculatus was, however, taken in the trawl off the Eddystone in May, 1910, after this paper was in manuscript. 


\begin{tabular}{|c|c|c|c|c|c|}
\hline \multirow{3}{*}{$\frac{\text { Date. }}{\text { 19-IV }}$} & \multicolumn{2}{|c|}{ (Z. norvegicus). } & \multicolumn{3}{|c|}{ II. $Z$. punctatus (? all this species). } \\
\hline & of egg. & $\begin{array}{l}\text { Diameter } \\
\text { of oil-globule. }\end{array}$ & Date. & of egg. $\quad$ Dian & $\begin{array}{l}\text { er } \\
\text { il-globule. }\end{array}$ \\
\hline & $\cdot 82$ & $\cdot 13$ & $17-\mathrm{II}$ & $1 \cdot 03$ & $\cdot 19$ \\
\hline , & $\cdot 86$ & $\cdot 132$ & $20-\mathrm{II}$ & $1 \cdot 04$ & $\cdot 17$ \\
\hline$"$ & $\cdot 84$ & $\cdot 13$ & $25-\mathrm{II}$ & $1 \cdot 02$ & $\cdot 195$ \\
\hline , & $\cdot 87$ & - & , & $1 \cdot 04$ & $\cdot 17$ \\
\hline , & $\cdot 87$ & $\cdot 125$ & $"$ & $1 \cdot 02$ & $\cdot 18$ \\
\hline ", & $\cdot 88$ & $\cdot 125$ & $4-\mathrm{III}$ & $1 \cdot 05$ & $\cdot 19$ \\
\hline$"$ & $\cdot 84$ & $\cdot 125$ & , & $\cdot 99$ (ca) & $\cdot 17$ \\
\hline $20-$ IV & $\cdot 90$ & $\cdot 15$ & 19-IV & $1 \cdot 01$ & $\cdot 19$ \\
\hline$"$ & $\cdot 83$ & $\cdot 13$ & 20-IV & $\cdot 99$ & $\cdot 175(?)$ \\
\hline$"$ & $\cdot 845$ & $\cdot 14$ & $28-\mathrm{IV}$ & $\cdot 99$ & $\cdot 175$ \\
\hline$"$ & $\cdot 84$ & $\cdot 125$ & $3-\mathrm{V}$ & $\cdot 96$ & $\cdot 18$ \\
\hline ", & .85 & $\cdot 10$ & , & $\cdot 98$ & $\cdot 18$ \\
\hline $12-\mathrm{V}$ & $\cdot 75$ & $\cdot 11$ & ", & .98 & $\cdot 18$ \\
\hline $18-\mathrm{V}$ & .80 & $\cdot 095$ & $12-\mathrm{V}$ & $\cdot 99$ & $\cdot 18$ \\
\hline$"$ & $\cdot 84$ & $\cdot 12$ & $24-\mathrm{V}$ & $1 \cdot 01$ & $\cdot 178$ \\
\hline ", & $\cdot 81$ & $\cdot 13$ & $"$ & $\cdot 98$ & $\cdot 17$ \\
\hline $24-\mathrm{V}$ & $\cdot 86$ & $\cdot 13$ & , & .94 & $\cdot 175$ \\
\hline 14-VI & $\cdot 82$ & $\cdot 11$ & ", & $\cdot 92$ & $\cdot 175$ \\
\hline$"$ & $\cdot 82$ & $\cdot 11$ & $"$ & $\cdot 96 \times \cdot 98$ & $\cdot 17$ \\
\hline ", & $\cdot 80$ & $\cdot 12$ & & & \\
\hline $28-\mathrm{VI}$ & $\cdot 82$ & $\cdot 125$ & & & \\
\hline ", & $\cdot 82$ & $\cdot 11$ & & & \\
\hline , & $\cdot 84$ & $\cdot 12$ & & & \\
\hline
\end{tabular}

I have not the slightest doubt in referring all the eggs of Column I to $Z$. norvegicus. It will be noted by reference to Table I that the localities of their capture belonged in general more to the open-sea waters than is the case for the larger eggs of Column II. Most, if not all, of the latter I ascribe to $Z$. punctatus. Not only do the dimensions of the egg and oil-globule fall into two fairly distinct groups, but also, as far as could be observed, the hatched-out larvae from the smaller eggs exhibited one type of characteristic pigmentation (identified by Ehrenbaum, op. cit., with $Z$. norvegicus), and those from the larger eggs another type of pigmentation, which is identical with that shown by Holt's "Species X" (11b, Figs. 20 and 21), referred by Ehrenbaum, with a query, to $Z$. punctatus. I do not doubt but that this is its species. There is only one other species possible and that is Z. unimaculatus, a much less common fish in our area. Moreover, the latter has not occurred in our collections of post-larval fishes for the years 1906,1908 , and 1909 , although $Z$. norvegicus is common and $Z$. punctatus 
occasionally recorded in each year for the months April, May, and June. The difficulty, if not impossibility, of distinguishing the egg of Z. unimaculatus by its dimensions may be seen by a comparison of measurements of the eggs of this species, which are definitely known from having been obtained from ripe females $(\cdot 92-93 \mathrm{~mm}$. for unfertilized, and $\cdot 90-99 \mathrm{~mm}$. with oil-globule $\cdot 16-18 \mathrm{~mm}$. for fertilized ova*) with Column II in the above list. There is indeed one egg (marked with a ?) in the above series which I had some ground for regarding as possibly $Z$. unimaculatus. This was taken on the 20 th April in Cawsand Bay. Unfortunately my recorded observations of this egg and the subsequent larva are very meagre. Just before the outgrowth of the caudal rudiment there was no pigment whatever on the embryo. The larva, which hatched out on the 24th April, had a length within the first few hours of larval life of $2.4 \mathrm{~mm}$., the pre-anal length being $1.07 \mathrm{~mm}$. This agrees almost exactly with Holt's newly hatched specimen from an artificially fertilized egg of $Z$. unimaculatus (11c, p. 46, and 11f, Fig. 89). My brief notes upon the larva state that yellow was the predominant pigment, occurring in moderate-sized round and stellate chromatophores over body, yolk-sac and unpaired fins, except at the posterior extremity of the latter. Along the margin of the unpaired fins the pigment was dendritic. Black pigment consisted of numerous very fine dots, scattered with the yellow all over the body, fins, and yolk-sac. However, on the 27th the pigmentation had assumed the same form, which I found at the same stage in the other larvae hatched from the larger group of Top-knot eggs and which I regard as typical of Z. punctatus. Its identity with Z. unimaculatus, therefore, can be based only upon the dimensions of the egg and newly hatched larva, for which comparison there is still too little material. Of course there is the possibility of a close resemblance between the pigmentation of the later vitelligerous larval forms of the two species.

It will be noticed that my above lists indicate a somewhat different period for the occurrence of the two groups of eggs, Group I (Z. norvegicus) being taken from 19th April to 28th June, and Group II ( $Z$. punctatus) from 17 th February to 24th May. This difference is, however, probably more apparent than real, for before April I was not able to get any samples from further seaward than the entrances to Plymouth Sound, which would leave the habitat of $Z$. viorvegicus neglected for the commencement of the season.

I may now give a more detailed account of the characters and especially the pigmentation of the two undoubtedly occurring species.

* Cf. Holt, 11d, p. 128. 


\section{Zeugopterus norvegicus, Coll. Norwegian Top-knot.}

The oil-globule is commonly pale green and the yolk-sac slightly rugose. Before the outgrowth of the caudal rudiment the periblastic pellicle of the oil-globule becomes visible, and fine black chromatophores appear on the embryo and yolk-sac. They are very closely set on the former but less dense and mostly stellate in form on the latter. Over the whole embryo and yolk-sac there is a pale greenish yellow tint, but no separated, coloured chromatophores are visible as yet. Yellow pigment cells soon appear on the embryo and yolk-sac, and by the end of embryonic life they become conspicuously predominant. The black chromatophores show dense, rounded centres, from which fine ramifications proceed. Some of the few yellow chromatophores on the yolk-sac are stellate, with no specially large centre. On the trunk of the embryo, just before hatching, they are large and of vague outline, and so close together as to give the effect of a diffuse tinting along the whole length of the body, except the extreme caudal end. Black pigment is fairly uniformly distributed over the body, but shows some concentration into dorsal and ventral lines. A newly hatched larva measures $2.58 \mathrm{~mm}$., with a pre-anal length of $1.16 \mathrm{~mm}$. The snout projects conspicuously forward over the yolk-sac, and the anus is situated some little distance behind the posterior end. Ehrenbaum (op. cit.) describes the position of the oil-globule as usually at the middle of the ventral side of the yolk, but I have generally found it postmedian. The pectoral fins are well developed. The pigmentation is extremely rich. A diffuse yellow effect, which is evident to the naked eye, is produced by the close proximity of the large chromatophores (greenish yellow by reflected light), which are distributed over the body, fins, and yolk-sac, most densely along the dorsal and ventral contours and the upper and lower margins of the unpaired fins. Black chromatophores are more abundant, but smaller and much less conspicuous. A very characteristic feature is the stopping short of the pigmentation of the unpaired fins some little distance from the caudal extremity, so that this part of the larval tail is quite clear. The same arrest of yellow chromatophores is seen on the body itself, but small black pigment spots occur as far as the posterior extremity. A further conspicuous character of this species is the regular, fringe-like arrangement of both the black and yellow pigment along the outer margin of the unpaired fin, in the early stages of the larval development. The fringe-like effect is accentuated by the finely pectinate form of the chromatophores in this region. With the absorption of the yolk the intensity of the yellow pigment increases, although undergoing 
little change in distribution. At $3 \mathrm{~mm}$. length, for example, with the yolk almost absorbed, the general arrangement of pigment is as above. Head and body (except posterior extremity) appear of an almost uniform bright yellow. In the anterior half of the post-anal region the notochord shines white through the yellow, but in the posterior part the yellow is so dense as to obscure it. The coloured pigment is more concentrated on the head, along the dorsum, and about the rectum. The fringe formed by the line of closely applied dendritic or pectinate chromatophores along the margin of the unpaired fins, has a somewhat brownish tint, which is not seen on other parts of the larva. In the anal fin, the fringe begins some distance posterior to the anus. Black pigment is most dense on the ventral surface at the level of the pectoral fins and above the anterior part of the remains of the yolk-sac, where the vestige of the oil-globule now measures about $0.03 \mathrm{~mm}$.

A larva in which the yolk had been fully absorbed (ca. $3 \mathrm{~mm}$. long) showed less distinctness as to the marginal pigment, and a concentration-more particularly of the black chromatophores-in the pigment of the unpaired fins, about half-way between the anus and caudal extremity.

Reticulate markings and small papillae on the epidermis are commonly found both in late embryonic and in larval stages.

To summarize the main facts ascertained for $Z$. norvegicus:-The spawning season, in the Plymouth neighbourhood, extends from April to June, probably beginning somewhat earlier than the former month. The pelagic eggs have a homogeneous yolk and a single oil-globule, which is frequently of a greenish yellow tint. The average diameter of the egg is $0.854 \mathrm{~mm}$. in April and $0.817 \mathrm{~mm}$. in May and June, the limits lying between 0.75 and $0.90 \mathrm{~mm}$. The oil-globule measures $0.095-0.15 \mathrm{~mm}$., the average diameter being $0.122 \mathrm{~mm}$. Embryonic yolk-sac and larval pigments are yellow (bright greenish yellow by reflected light) and black, the former predominating and being visible to the naked eye in the larva. The body and yolk-sac of the newly hatched larva are rather elongate, the total length being about $2.58 \mathrm{~mm}$. (Ehrenbaum gives $2 \cdot 52-2.76 \mathrm{~mm}$.). The anus is situated a short distance behind the posterior edge of the yolk-sac, and at about $\frac{6}{13}$ the body length from the snout. The characteristic feature of the vitelligerous larva is the marginal pigmentation of the unpaired fins and their total lack of pigment in the caudal region. 


\section{Zeugopteris punctatus (Bl.).}

Before the outgrowth of the caudal rudiment, the body of the embryo is beset with fine, black chromatophores which are chiefly, if not entirely, on the dorsal surface. A few black chromatophores of larger size are found over the oil-globule, and there may be a small number of black spots on the yolk-sac, which is beset with a moderate number of roundish, yellow chromatophores. The latter pigment occurs in smaller spots on the head and body of the embryo. At this stage the perivitelline space is somewhat large, and the oil-globule is contained in a very distinct periblastic pellicle.

With the growth of the free caudal region (Fig. 2) a marked increase in the size and number of chromatophores takes place. The yellow spots over the yolk-sac now acquire a stellate form, but on the embryo they still occur as patches disposed over the head and body. Yellow does not extend quite to the tip of the caudal extremity as the black does. The black chromatophores over the oil-globule have increased in number, and are the largest of all. Over the yolk-sac they are small and sparingly scattered. Minute black specks occur over the whole body, from anterior to posterior extremity, being most concentrated along the dorsal and ventral contours, dendritic outgrowths from which extend to the embryonic fin. The pectoral fins are relatively well developed, and rudiments of the pelvic fins are visible.

Three larvae observed soon after hatching (Fig. 9) had lengths of $2.90,2.92$, and $2.93 \mathrm{~mm}$., the pre-anal lengths being respectively $1 * 44$, 1.40 , and $1.45 \mathrm{~mm}$. The anus is therefore appreciably nearer the median position than in the case of Zeugopterus norvegicus, which otherwise it very closely resembles both in general form and in the distribution of its black and yellow pigmentation, the former occurring in mostly small, fine specks and the latter in large, stellate chromatophores. The yolk-sac is elongate and bears the much-reduced oilglobule at its posterior end. As in the above species, the marginal pigment of the unpaired fins is of most diagnostic importance. Immediately after hatching I found some resemblance to the arrangement in Z. norvegicus, but the "fringe" formation is not so well marked, and within one day a striking change has taken place which appears to be quite characteristic of $Z$. punctatus, at least as distinct from $Z$. norvegicus. I can, of course, make no comparison with $Z$. bimaculatus, though it is to be noted that Holt's newly hatched larva from an artificially fertilized egg of $Z$. bimaculatus showed no fringe-like occurrence of pigment along the upper and lower margins of the unpaired fins, which I observed in my larvae of both species. 
The one-day-old larva (length $3.42 \mathrm{~mm}$.) shows a complete modification of the marginal fringe of the early stage by its breaking up into a series of separate large pectinate and dendritic patches, eight of these patches occurring in the dorsal and five in the anal fin. This exactly resembles Holt's "Species X" (11b, Figs. 20 and 21), which Ehrenbaum (5b, p. 206) considers as probably identical with Zeugopterus punctatus. Besides the above-mentioned characteristic, large, marginal chromatophores, in each of the unpaired fins there is a series of fairly large stellate chromatophores, midway between these and the trunk contours, a single row in the dorsal and a double row in the anal fin. The last $0.5 \mathrm{~mm}$. of the tail end is free from pigment in the fin membrane, but fine black chromatophores extend to the caudal extremity of the trunk. Yellow and black chromatophores are scattered fairly uniformly over the whole body, with a certain amount of concentration along the dorsal and ventral contours.

On the third day (Fig. 10) still further local concentration into patches has taken place, but the general form of the pigmentation remains the same. Black pigment now appears in the eye, and the prominent pectoral fins bear dendritic yellow and rounded black chromatophores. The yolk-sac-with the yolk somewhat more than half absorbed-is very elongate, so that its ventral contour is practically straight.

To summarize:-The spawning season of $Z$. punctatus in this neighbourhood extends from the middle of February to May. The pelagie eggs have a homogeneous yolk and one oil-globule. The diameter of the egg averages $1.03 \mathrm{~mm}$. in February-March and $0.98 \mathrm{~mm}$. in AprilMay, the limiting sizes being $0.92 \mathrm{~mm}$. and $1.05 \mathrm{~mm}$. The diameter of the oil-globule is $0 \cdot 17-0.19 \mathrm{~mm}$. Embryo and yolk-sac bear black and yellow pigment, the latter becoming conspicuously predominant in the late embryo and larva. Within one day after hatehing, the larva exhibits characteristic stellate or pectinate and dendritic patches of yellow pigment associated with black in its unpaired fins, usually eight in the dorsal and five in the anal fin. The newly hatched larva measures $2 \cdot 90-2 \cdot 93 \mathrm{~mm}$. (or possibly less), and the anus is only slightly (if at all) anterior to the median point.

\section{Gadus.}

Our tow-net samples of Gadus eggs have not been sufficiently numerous to enable certain conclusions as to their identity to be made in the great majority of cases. This is not due to the absence or scarcity of members of the genus from our neighbourhood, but to the fact that the open-sea water some distance from the coast was not townetted till April, when the spawning season of the Plymouth gadoids is 
almost over. It is a fact of common knowledge to the Plymouth fishermen that the whiting ( $G$. merlangus), bib ( $G$. minutus), pout (G. luscus), and pollack (G. pollachius) are to be found nearer the shore in summer and autumn than in winter and early spring, when the breeding season occurs. This habit of migrating to deeper water for the colder months of the year they have in common with the other important food fishes of the Plymouth district, such as the Pleuronectidae and gurnards. Very many more observations, both physical and biological, are necessary before definite conclusions can be made as to the real causes of these phenomena. The off-shore migration in winter and the corresponding approach to shallow water in summer may, in some cases, follow the seasonal distribution of food, but I do not think this is at most more than a partial explanation. The fact that the temperature of the water in the deeper parts of the Channel is appreciably higher than that of the more inshore parts of the Channel in the coldest months of the year, may be taken as a sufficient reason for the majority of fishes preferring to seek the outer grounds at this time. That conditions directly related to the phenomenon of spawning are involved in this migration (which certainly coincides with the ripening and liberation of the sexual products of most of the species) may be concluded from analogy with the cases already worked out under less complicated conditions, e.g. the plaice and cod, by Johs. Schmidt (21c), who has shown that these and other species show a special sensitiveness to external conditions, especially of temperature, in relation to spawning, and therefore make special and well-marked migrations.

So far I have not been able to obtain direct proof of extensive spawning of our four common Plymouth species of Gadus on the offshore grounds because winter samples of plankton from such regions have not been collected, but the general fact may be taken for granted. With due precautions one may accept the occurrence of pelagic postlarvae, such as were captured in the young-fish trawl in April and subsequent months, as evidence giving more or less quantitative information as to the spawning times and the relative extent of the reproduction of the various Gadus species in this neighbourhood. As far as can be judged from our takings of the small fry-and evidence from the fisheries points to the same conclusion for the adultsGadus merlangus is the most abundant, very many post-larvae of this species having been taken, especially in May and June. Next in abundance comes $G$. minutus, which has an almost similar period of occurrence, if anything earlier than the whiting. The early pelagic post-larval stages of the pollack have always in my experience been less common than the two foregoing, but they are very abundant, at a 
size of about $5 \mathrm{~cm}$., close up to the rocks on the shores of the Sound. Post-larval stages of $G$. luscus, which appears to be the least abundant of our four common representatives of the genus, are not infrequent but are never numerous, and they disappear from the samples somewhat earlier than the other three.* Other species, such as G. morrhua (cod) and $G$. virens (coal-fish), are known, but are very occasional spawners in this neighbourhood.

The specific identification of the pelagic ova by the form and pigmentation of embryo and larva is difficult and sometimes impossible, owing to their great similarity. Pollack, indeed, is said to show no yellow pigment at all in the embryo and early larva (14e, p. 171), while the other three species above mentioned as common to these waters do so to a greater or less extent. We cannot feel that we are on safe ground here, however, in dealing with individual fishes on this point, since the G. minutus larva is described by Raffaele from the Mediterranean and by Holt from the west of Ireland as having only black pigment, and in several cases the appearance of yellow chromatophores has been noted as an accompaniment to an unhealthy condition (cf. 11d, p. 140).

The impossibility of separating the species with certainty by reference to dimensions of the ova is indicated by the list which I give below of measurements of eggs taken from ripe female fishes.

\begin{tabular}{|c|c|c|c|}
\hline Species. & Diameter of Egg. & Month. & Authority. \\
\hline $\begin{array}{l}\text { G. luscus } \\
\text { G. pollachius }\end{array}$ & $\begin{array}{c}0.95-1 \cdot 07 \\
1 \cdot 02 \\
0.9906-1 \cdot 0287 \\
1 \cdot 07 \\
\text { A little below } 1 \mathrm{~mm} . \\
1 \cdot 05-1 \cdot 15 \\
1 \cdot 13 \dagger \\
1 \cdot 14 \\
1 \cdot 13\end{array}$ & $\begin{array}{c}\text { April } \\
\overline{-} \\
\overline{-} \\
\text { January } \\
- \\
-\end{array}$ & $\begin{array}{l}\text { Ehrenbaum } \\
\text { Cunningham } \\
\text { McIntosh } \\
\text { Holt } \\
\text { Raffaele } \\
\text { Cunningham } \\
\text { Holt } \\
\text { McIntosh (artificially } \\
\text { fertilized egg) } \\
\text { Holt }\end{array}$ \\
\hline
\end{tabular}

* A general idea of the seasonal occurrence of the young fry may be obtained from the following particulars taken from my records for 1909 of catches of the young-fish trawl :-

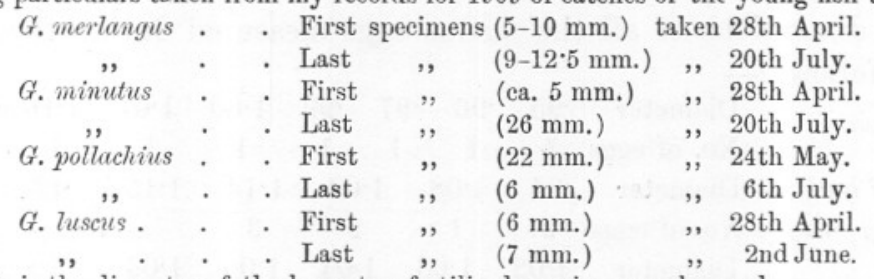

† This is the diameter of the largest unfertilized ovarian egg observed. 


\begin{tabular}{c|c|c|c|}
\hline Species. & Diameter of Egg. & Month. & \multicolumn{1}{c|}{ Authority. } \\
\cline { 2 - 4 } G. merlangus & $1 \cdot 125$ & - & $\begin{array}{c}\text { MeIntosh and Prince } \\
\text { (artificially fertilized) } \\
\text { Heincke and Ehrenbaum } \\
\text { (artificially fertilized) } \\
\text { Heincke and Ehrenbaum } \\
\text { (artificially fertilized) } \\
\text { Heincke and Ehrenbaum } \\
\text { (artificially fertilized) } \\
\text { Williamson (artificially } \\
\text { fertilized) }\end{array}$ \\
\hline
\end{tabular}

From this evidence we can merely state that the average size of the egg shows an increase in the order in which the species are enumerated above, but the difficulty arising from overlapping is sufficiently formidable, seeing that the largest size for $G$. minutus may be larger than that of the smallest whiting.

The size of the newly hatched larva shows variation, which may to some extent be taken as a guide to the species, but on this point, to an even greater degree than is the case with regard to the egg, the data hitherto available are very scanty and afford little satisfactory information. With some degree of certainty we may take it that the G. minutus larva is the smallest, but no measurement of the product of artificial fertilization is on record. Holt (11b) records as $G$. minutus a larva of $2.75 \mathrm{~mm}$. length hatched from a pelagic egg of $1.07 \mathrm{~mm}$. The $G$. luscus larva is probably bigger, and that of $G$. merlangus is certainly bigger still. Ehrenbaum (5d, pp. 234 and 238) gives ca. $3 \mathrm{~mm}$. or somewhat smaller for the former and 3.2 to $3.5 \mathrm{~mm}$. for the latter species. G. pollachius is so far too imperfectly known for us to state anything as to its larval dimensions. Holt (11d, p. 141) ascribes to this species certain pelagic ova of 1.40 to $1.45 \mathrm{~mm}$. diameter taken in February, and mentions that the larva was $4.2 \mathrm{~mm}$. long and had black pigment only. There seems to me to be little doubt as to the correctness of this identification, and it seems probable that further investigation of the eggs and larvae of this species will prove them to be larger in general than those of $G$. merlangus.

The dimensions of all the Gadus eggs measured during the season are as follows:-

\begin{tabular}{llccccccc} 
February & Diameter & .95 & .96 & .97 & .99 & 1.00 & 1.07 & $1.16 \mathrm{~mm}$. \\
April and & No. of eggs & 3 & 1 & 1 & 1 & 1 & 1 & 1 \\
early May & Diameter & .94 & 1.08 & 1.09 & 1.14 & $1.13 \times 1.17$ & $\mathrm{~mm}$. \\
\multirow{2}{*}{ June-August } & No. oggs & 2 & 1 & 2 & 3 & \multicolumn{2}{c}{1} & \\
& Diameter & 1.02 & 1.03 & 1.04 & 1.05 & 1.06 & $1.12 \mathrm{~mm}$. \\
\cline { 2 - 9 } & No. of eggs & 1 & 1 & 2 & 1 & 1 & 1
\end{tabular}




\section{Gadus minutus and Gadus luscus.}

On 8th April a ripe female $G$. minutus was taken in the trawl about 7 miles south-west of the Eddystone. Eleven ova from this measured 0.91-1.02 mm., the average diameter being 0.939 $\mathrm{mm}$. Artificial fertilization was attempted, but development was stopped by death at the blastula stage. Eight eggs taken in the tow-nets on the same day and in the same locality had diameters of $0.94,1.08,1.09,1.13,1.14$ (two eggs), and $1.13 \times 1.17 \mathrm{~mm}$. (the last not exactly spherical). The embryonic form of all appeared practically identical. Round and dendritic black chromatophores first appear on the embryo, and at a later stage a diffuse yellowish tint appears over both embryo and yolk-sac. Just before hatching the black chromatophores are most densely distributed in the posterior half, and there is little or none of this pigment on the head. One or two black stellate chromatophores usually appear on the yolk-sac, ${ }^{*}$ to which also outgrowths from the pigment cells in the otocystic region generally extend. The head and anterior part of the embryo are covered with a diffuse greenish yellow tint; the yolk-sac occasionally shows distinct yellow chromatophores at this stage, but more usually is also diffusely tinted. Only once I noticed distinct chromatophores on the embryo before hatching. I noted no pigment on the embryonic fin at this stage. Two larvae hatched out from eggs of 1.08 and $1.09 \mathrm{~mm}$. diameter measured (a) $2.65 \mathrm{~mm}$., of which $1.35 \mathrm{~mm}$. was the pre-anal length, and (b) ca. $2.9 \mathrm{~mm}$. with a pre-anal length of ca. $1.5 \mathrm{~mm}$. A third larva, (c), slightly more than twenty-four hours old, measured $2.9 \mathrm{~mm}$. total length $(1.2 \mathrm{~mm}$. from snout to anus). This was from the egg of $1.13 \times 1.17 \mathrm{~mm}$. diameter. A fourth larva, (d), from the egg of $1 \cdot 14 \mathrm{~mm}$. diameter, measured when the yolk was absorbed, had a length of $3 \mathrm{~mm}$., of which $1.28 \mathrm{~mm}$. was pre-anal. The pigmentation consists of black chromatophores mostly dendritic, distributed along the dorsal and ventral contours, in the peritoneum, a little on the top of the head and about the pectoral region. In specimen (a), however, the pigment extends to the tip of the caudal region, while in (b), which has heavier pigmentation, the last $0.3-0.4 \mathrm{~mm}$. of the tail is bare.

This difference, considered together with the difference of larval size, suggests a difference of species which was impossible to detect in the two eggs so similar in general character and only differing by $0.01 \mathrm{~mm}$. in diameter. From which egg each larva was produced I

\footnotetext{
* This was noted on eggs which gave rise to different types of larvae, e.g. (a) and (b). See above.
}

NEW SERIES.-VOL. IX. NO. 1. OCTOBER, 1910. 
am not able to state, because I had kept them together in the same vessel, regarding them as of the same species; but the very similarity of eggs makes this point a matter of indifference. The larva (a), which is $2.65 \mathrm{~mm}$. long and pigmented to the caudal extremity, I regard as Gadus minutus. Larva (b), on the other hand, which is slightly larger (ca. $2.9 \mathrm{~mm}$.) and shows heavier pigmentation, stopping short so as to leave the caudal extremity bare, I consider is very probably G. luscus (cf. 10, Taf. X, Figs. 20 and 21). Larva (d) (length $3 \mathrm{~mm}$. with yolk absorbed) resembles (b), the posterior $0.5 \mathrm{~mm}$. of the caudal extremity being unpigmented. The small size for this stage of development does not rule out the probability of its being $G$. luscus, Larva (c) shows black pigment of less intensity, most of it occurring along the ventral post-anal contour as far as the caudal extremity and above the gut. There are only four dorsal post-anal chromatophores, and these are not nearly so strongly marked as the ventral ones. This I regard as $G$. minutus, especially on account of there being a distinct resemblance to the early post-larval forms of this species, which have been carefully described by Schmidt (21a and b), and which are common in my own collections. In the same way the bare-tailed larvae (b) and (d) suggest the now well-known larval pout.* As to the occurrence of yellow pigment, all four specimens showed yellow chromatophores, with more or less distinctness on body, unpaired fins, and yolk-sac, but in the post-vitelligerous specimen (d) this colour had almost vanished except from the head (cf. McIntosh, 14c, p. 240).

Three planktonic eggs of $0.95 \mathrm{~mm}$. diameter, which were taken in the West Channel (entrance to Plymouth Sound) on 11th February, may be either $G$. minutus or $G$. luscus. One-day-old larvae measured 2.95 and $2.8 \mathrm{~mm}$. The black pigment consists of relatively large stellate chromatophores on the head, a dorsal series which become smaller and less closely placed towards the posterior extremity, and a much weaker ventral series consisting of about nine post-anal chromatophores and a faint line dorsal to the gut. There are small specks of yellow pigment on the body and embryonic fins, most strongly markect along the body contours and along the proximal margins of the fins, but very faint in the caudal region. The larval pigment at this stage cannot be said to show any approach to either the bib or

* While using this similarity of larval pigment to that of definitely known post-larval stages as evidence assisting to indicate the identity of a larva hatched from a Gadus egg taken in the tow-net, I think it necessary to point out that this similarity should not always be expected in the larval stages. As positive evidence it is helpful, but as negative evidence it is without value. Under certain conditions-chiefly of higher than normal temperature-I have noticed a precocity in development of pigment. The same phenomenon has been noted by Holt (cf. 11a, p. 454). 
pout type of post-larval pigment. It resembles $G$. merlangus, but the small size seems to preclude that species. A larva of similar character hatched from an egg of $1.00 \mathrm{~mm}$. diameter, taken from the same locality on 25 th February, measured ca. $275 \mathrm{~mm}$. when more than a day old.

The next noteworthy capture of Gadus eggs took place late in August, an unusual time for the spawning of any members of the genus in our area. On 26th August two eggs of 1.02 and $1.06 \mathrm{~mm}$. diameter were obtained in the young-fish trawl, but they died before hatching. The following day six eggs were captured of diameter 1.03-1.05 mm. In embryonic characters these resembled what I have above described as $G$. luscus. An early larva from one of them had a length of ca. 2.5 $\mathrm{mm}$. A second larva which had absorbed practically all its yolk was $3.32 \mathrm{~mm}$. long, of which $1.22 \mathrm{~mm}$. was pre-anal. At this stage the anus was still apparently imperforate; the eyes dark blue with considerable black pigment, the mouth large with the relatively massive lower jaw slightly protruding. There is well-marked indentation behind the mid-brain and a typical large supra-cephalic ampullation, which extends as far back as the level of the anus. The pectoral fins are large and fan-like. The type of pigmentation strongly suggests G. luscus. Black chromatophores are distributed post-anally as very distinct dorsal and ventral lines, which stop short at a distance of ca. $0.9 \mathrm{~mm}$. from the posterior extremity, so that the last part of the tail is quite unpigmented. The dorsal line arises in the occipital region and the ventral at the base of the pectoral fin, whence it continues backwards at the level of the dorsal edge of the gut. There is also black pigment at the tip of the snout, at the end of the mandible, below the throat, and a few lateral chromatophores on the trunk. In this specimen the latter were adjacent to the dorsal series, but in another they were mainly on the ventral half of the body posterior to the anus. No yellow pigment at all was observed in the late larval stages. The early larvae were very cursorily examined and I have no notes as to the presence of this colour. In the embryonic development a diffuse yellow tint was visible on the yolk-sac and about the contours of the trunk.

\section{Gadus merlangus.}

Only three eggs in all were taken, which may with probability be referred to this species. The first, taken at the western entrance to the Sound on 25th February, was $1.16 \mathrm{~mm}$. in diameter, but was killed by the low temperature before hatching. The second was obtained from a haul of the young-fish trawl in Cawsand Bay on 28th April. No record was made of the size of the egg, but the newly hatched larva had a length of $3.44 \mathrm{~mm}$. (pre-anal length, $1.42 \mathrm{~mm}$.) 
and the yellow and black pigmentation typical of G.merlangus. A third whiting egg was taken on 12th July, about $1 \frac{1}{2}$ miles south of Rame Head. The diameter was $1.12 \mathrm{~mm}$. and the length of the larva within the first day $3.58 \mathrm{~mm}$., the distance from snout to anus being $1.58 \mathrm{~mm}$.

The fewness and infrequency of the appearance of whiting eggs in my collections are undoubtedly due to the fact that our tow-nettings have not been taken anywhere near the off-shore breeding haunts of the species at the time of their spawning season.

\section{Onos, Risso (= Motella, Cuvier). The Rocklings.}

It is an open question whether our knowledge of the occurrence of the members of this genus in the Plymouth neighbourhood is complete and exact, but certainly the presence of more than one species has complicated the task of fully identifying the rockling eggs, which have long been well known as occurring here in abundance. The most common species found here is O. mustela, $\mathrm{L}$, and 0 . tricirratus (Bloch) is also known, while Holt (11d, p. 143) speaks of "the undoubted existence in the district of $M$. cimbria and $M$. maculata, and possibly of other forms which may require specific distinction." I have no personal knowledge of the occurrence of the two latter species, but I may mention that a form identified as Motella fusca, Moreau, by Garstang and Balfour Browne was taken in April, 1901, on the shores of Plymouth Sound.*

However, the problem of denoting the species of the pelagic ova commonly occurring at Plymouth, is mainly one of deciding which other species besides the abundant 0 . mustela are represented. My task of identification has been aided by the recent publication by Ehrenbaum (5c, p. 237, and 5d, p. 284) of descriptions of the ova and larvae of $O$. mustela, L., and 0 . cimbrius, L. In regard to the latter species I need only say that it does not appear to be represented in my samples of ova, nor do I know of any record of the occurrence of the adult in this district. $\dagger$. mustela, on the other hand, is the prevailing species, and what I was led to expect, from the abundance of the fish in Plymouth Sound, is confirmed by comparison with Ehrenbaum's description of the egg and larva of the species. He gives the average diameter of the ova of 0 . mustela as varying (off Heligoland) from $0.878 \mathrm{~mm}$. in February to 0.736 in June, and the peculiar pigmentation of the late embryo and early larva as the chief diagnostic character (at least as far as distinguishes it from $O$. cimbrius), viz. the arrangement of the post-anal

* Journ. M.B.A., N.S., VI., p. 626.

† A small immature specimen of 0 . cimbrius was, however, taken in Whitsand Bay on the 3rd March, 1910, which is, I believe, the first record of the species for the Plymouth neighbourhood, 
black pigment into two groups, the first a short distance behind the anus, usually confined to the ventral half of the body, the second in the form of a band from the dorsal to the ventral contour, besides which there is, in the hypural region, a small patch of pigment which has outgrowths to the marginal fin. O. cimbrius shows only one of these post-anal pigment groups.

\section{Onos mustela, $\mathbf{L}$.}

To come to the consideration of my own specimens, they can with very little exception be designated Onos mustela. There is, of course, the bare possibility that the eggs and larvae of some other species of rockling, which are at present unknown, may so closely resemble those of 0 . mustela as to have been indistinguishable from them by me. But even if such were the case, the number so included would be quite inappreciable against the total, which are undoubtedly 0 . mustela. These eggs occurred in my tow-net and young-fish trawl plankton samples from 11th February to 25th June, and again in August and September. The diameter varied from 0.72 to $0.83 \mathrm{~mm}$., averaging 0.77 for February to March, 0.78 for April, and 0.72 for May to June. The diameter of the oil-globule varied from 0.13 to $0.18 \mathrm{~mm}$. It sometimes happened that the size of the oilglobule was the reverse of being proportional to the size of the egg, i.e. the larger eggs of a sample had the smaller oil-globules, which I thought might possibly be significant of a specific difference, but observations of the resulting larvae disproved this. The oil-globule, which may be subdivided into two or three in the early stages, commonly has a more or less greenish and sometimes a cupreous tint. The yolk surface is somewhat corrugated. By the time the embryo has developed a caudal rudiment, small black chromatophores appear generally in a double line along the body, on the head, and in the pellicle of the oil-globule. They soon increase in size, and may become stellate, especially the anterior ones. Just before hatching the two characteristic post-anal groups (or "zones") of pigment are generally quite distinct. One of my smallest newly hatched larvae measured $1.88 \mathrm{~mm}$. (the pre-anal length being $0.76 \mathrm{~mm}$.), and the largest size I have recorded for this stage is $2.32 \mathrm{~mm}$. The black pigment, which is mostly stellate and dendritic, is distributed upon the head, in the peritoneum, over oil-globule, laterally on the trunk over the anus, in the two large distinct post-anal groups above mentioned, and in the hypural region. These groups or zones are formed by the occurrence of short dorsal and ventral bars of black pigment spots, more or less fused together, from which dendritic outgrowths extend laterally. Sometimes such a bar may consist of only two or even one large 
chromatophore. Ehrenbaum states that the anterior group is usually confined to the ventral half of the body, but I have very often found it possessing a well-marked dorsal bar. The extent and intensity of these bars and groups of pigment, however, are subject to some variation. With the absorption of the yolk the post-anal pigment diminishes, especially in regard to the dorsal chromatophores, and when the yolk is entirely absorbed the latter have generally-though not always-entirely disappeared, leaving three relatively small chromatophores along the ventral contour corresponding to the three previous groups. At this stage the pectoral fins are well developed; but the ventrals, which soon afterwards become such a conspicuous feature of the post-larva, are rudimentary. My 0. mustela eggs were taken for the most part in Plymouth Sound and some in Cawsand Bay, while none were taken in more open water than Whitsand Bay, which is in keeping with the littoral haunts and the penchant for the vicinity of brackish water of the parent fish (cf. Holt, 11d, p. 143).

\section{Onos, Species A (? tricirratus, Bl).}

Two eggs which may probably be referred to this species occur in my samples, one taken on 28 th June 3 miles S. by W. of Rame Head, and the other taken on 30th August 3 miles W.N.W. of Rame Head. The identification is chiefly based upon the similarity of the larva to that of 0 . tricirratus, described by Raffaele (20,pp. 37 and 38 , Tav. I, Figs. 26 and 27; Tav. III, Figs. 2 and 3) from an egg of $0.74 \mathrm{~mm}$. diameter, which had an oil-globule of $0 \cdot 218$. The larva is characterized by the possession of less pigment than 0 . mustela or 0 . cimbrius. It is practically limited to one clearly defined zone of black pigment across the middle of the post-anal part of the body and a line of peritoneal pigment dorsal to the gut (op. cit., Tav. III, Figs. 2 and 3). The earlier of my eggs had a diameter of $0.84 \mathrm{~mm}$, and the later one $0.78 \mathrm{~mm}$. The oil-globules measured respectively 0.16 and $0.145 \mathrm{~mm}$. The embryonic pigment spots, which are small at their first appearance, become in the later stages relatively large in size, although few in number. The isolated mid-post-anal group of chromatophores is very conspicuous. In my second specimen I noted that this group consisted of six ventral chromatophores with three dorsal and two lateral ones, which, before hatching took place, formed a dense band around the embryo by their enlargement and partial fusion. Black appears in the eyes shortly before hatching. In both specimens only one chromatophore was to be seen over the oil-globule. The newly hatched larva from my later egg (Fig. 14) measures $2.32 \mathrm{~mm}$., of which $0.94 \mathrm{~mm}$. is preanal. That from my June egg, measured when about one day old, 
had a length of $2.42 \mathrm{~mm}$., from the snout to the anus being $1.0 \mathrm{~mm}$. The pigmentation of the former consists of a very conspicuous midpost-anal patch, made up of a large dorsal and a large ventral chromatophore (the latter accompanied anteriorly by a relatively small pigment spot), a small hypural patch, while pre-anally there is a group of chromatophores on the side of the body in the pectoral region, a series dorsal to the gut, one large dendritic chromatophore below the anus and extending partially over the oil-globule, and some pigment in the eye and on the head. The pigmentation of my second larva at a slightly older stage, when most of the yolk had been absorbed, differed only from the above in being somewhat more densely aggregated. Two large dendritic chromatophores-one dorsal and one ventral-with outgrowths extending laterally as far as the notochord, constituted the mid-post-anal group, a continuous line of dendritic pigment ran along the whole peritoneal region, one large dorso-lateral patch of pigment occupied that part of the trunk above the base of the pectorals, two small chromatophores were on the head, and the iris was now completely black. Holt (11b, Pl. VI, Fig. 53) has figured a larva ("Species III (Motella?)") somewhat similar to this, but having an anterior group of post-anal pigment spots much resembling that of 0 . mustela, which it also approaches in having many pigment spots over the oil-globule. Ehrenbaum (5d, p. 278) considers this may possibly be 0 .tricirratus, $\mathrm{Bl}$. The egg had a diameter of $0.72 \mathrm{~mm}$. (and less) and an oil-globule of $0.17 \mathrm{~mm}$., and the larva in its first day was $2.20 \mathrm{~mm}$. long. My larvae certainly have a closer resemblance to Raffaele's O. tricirratus, Bl., than this of Holt's. I may mention, however, that Ehrenbaum (ibid.) warns one not to attach too much weight to Raffaele's identification of the parent fish as 0 . tricirratus, Bl., suggesting that the Naples observer did not wish to designate this species as distinguished from 0 . mediterraneus (L.), but merely referred to the common tricirrate form of the Bay of Naples, which appears to be O. mediterraneus $(\mathrm{L})$ (=0. tricirratus, Brünnich), and not O. tricirratus, Bloch (= Onos vulgaris, Yarr.). I do not see, however, that there is any solid ground for doubting Raffaele's identification in this case.

\section{Onos, Species $B$.}

A much more problematic form of larva, which I will term "Onos, sp. B," was hatched from a rockling egg taken in the young-fish trawl 2 miles S. of Rame Head on 2nd June. The egg had a diameter of $0.68 \mathrm{~mm}$., and its oil-globule $0.145 \mathrm{~mm}$. When the embryo had developed a short free caudal portion, it was marked with large black pigment spots, and the stellate chromatophores in the pellicle 
of the oil-globule were noted as being especially large. On the 5th of June the larva had hatched out. Its length when about one day old was $1.84 \mathrm{~mm}$. (pre-anal length $=0.84 \mathrm{~mm}$.). It showed the Motella characteristics as described above, except as regards the distribution of pigment in the pre-anal part of the body, which was practically wholly dorsal (see Fig. 15). From the snout to beyond the middle of the postanal part, there was a series of black chromatophores, most of which were large and possessed outgrowths extending over the upper part of the sides of the trunk, often as far as the level of the notochord. The most posterior group of this series contributed the dorsal bar of the typical Onos mid-post-anal zone. The corresponding ventral bar was present, as well as the usual hypural patch, but the only other pigment consisted of a single chromatophore below the anus and a group over the posterior part of the oil-globule. The absence of pigment from the peritoneal region is remarkable, and this fact especially inclines me to the view that we may possibly be dealing here with an abnormal specimen. Apart from this the pigmentation bears some resemblance to that shown by 0 . cimbrius (Ehrenbaum, op. cit.). From my present knowledge of Plymouth species of rocklings, however, I will not venture to suggest a definite species. Assuming that it is normal, it is certainly not $O$. mustela nor $O$. cimbrius; and if my previously described larva (Onos, sp. A) is indeed O. tricirratus, Bl., that species is also excluded. It seems to me that my "Onos, sp. A " may with far more probability be referred to Onos tricirratus, Bl., than may "Onos, sp. B." Then, by a process of exhaustion-always bearing in mind, however, that our knowledge of local Onos species cannot safely be regarded as complete -we have left Motella fusca, Moreau (which may probably be regarded with $M$. maculata of the same authority as varieties of 0 . mediterraneus, L.). It is at least possible that "Onos, sp. B," the larva with a preanal dorsal row of chromatophores and no peritoneal pigment, belongs to this species.

\section{Raniceps raninus, L. Frog-fish.}

Four eggs identified with this species were taken from a young-fish trawl, mid-water haul, in Whitsand Bay on 30th August. Holt obtained eggs of the same species from tow-nettings taken at various depths off Plymouth, in June, July, and August, 1897, which he recorded as unidentified but with apparently gadoid characters (11d, p. 145). In his Irish survey the same investigator had previously met with a similar egg and had described and figured it, with the twelvehour-old larva, as "Species VIII" (11a, p. 471, Figs. 27 and 36). He embodies his observations upon both Irish and Plymouth material in his Marseilles Museum Annals Memoir, suggesting as the possible 
parent fish Phycis blennoides, a rare visitor to this coast and one which had probably arrived in the track of the shoals of mackerel and scad (Caranx trachurus), which were present in unusual abundance in the inshore waters at the time of his Plymouth observations. Since that time, there have been no observations of planktonic fish eggs in the summer months here until the present year, so that the solution of the question as to whether the eggs belonged to a constant or intermittent visitor to these shores by the plan of noting the presence or absence of the eggs in successive years, has not been possible. It so happens that the present summer (1909) has also been characterized by a greater than usual abundance of mackerel and scad in the inshore waters of the Plymouth area, but whether this condition can be correlated with the presence of these eggs is doubtful. Heincke and Ehrenbaum (10, p. 258) have subsequently observed the egg as regularly occurring with summer plankton off Heligoland, and since Phycis blennoides, the only other fish to which it could with any probability be ascribed, is never found in Heligoland waters, they have identified it with Raniceps raninus-a quite well-founded conclusion, although the absolutely unquestionable identification by tracing back the egg to the parent still remains unaccomplished, since the ripe female is as yet unknown. Holt's Irish specimen measured $0.775 \mathrm{~mm}$. and had a colourless oil-globule of $0.14 \mathrm{~mm}$. diameter. The larva about twelve hours after hatching measured $2.68 \mathrm{~mm}$. Those taken by him at Plymouth at the end of June and in July measured from 0.84 to $0.91 \mathrm{~mm}$. in diameter, and the diameter of the oil-globule ranged from 0.16 to $0.17 \mathrm{~mm}$. In August the dimensions were 0.78 to 0.84 $\mathrm{mm}$. for eggs and 0.15 to 0.17 for oil-globule, and a newly hatched larva was $2.02 \mathrm{~mm}$. in length. The Heligoland eggs had a diameter of 0.755 to 0.912 and an oil-globule from 0.141 to $0.189 \mathrm{~mm}$. in diameter, while the length of newly hatched larvae varied from $2 \cdot 26$ to $2.90 \mathrm{~mm}$.

The dimensions of my specimens were as follows :-

$$
\begin{aligned}
& \text { Diameter of egg . . } 0.80,0.78 \times 0.79,0.81 \times 0.84,0.82 \text {. } \\
& \text { \# \#, oil-globule } 0.145,0 \cdot 145 \quad 0 \cdot 165 \quad 0 \cdot 157 \text {. }
\end{aligned}
$$

Two of them were ovoidal. The yolk is homogeneous, and the oilglobule is colourless. Just before the formation of the caudal rudiment, the head and body are liberally covered with medium-sized, black chromatophores, and yellow is making its appearance along the sides of the embryo. On the yolk-sac there is pigment of both colours, which is most dense in the postero-ventral region, a feature becoming more strongly marked as development proceeds. In the two larger specimens there are black and yellow chromatophores over the oil-globule, but 
they are absent from here in the two smaller eggs. Although precautions were taken to keep the temperature low by standing the jars containing ova in circulating tank-water, the eggs became infested by infusoria, whose presence is a usual accompaniment to unhealthy conditions. Development proceeded apace, however, and the next day the free caudal region had grown around the yolk, so as to almost meet the head. The bright yellow pigment of the embryo is now visible to the naked eye. It occurs in large dendritic chromatophores, which ramify and intermingle so as to produce a diffuse colouration over the whole of the pre-anal part of the trunk, and appears especially dense about the anus. There is a further band-like mass of yellow about the mid-post-anal region, and an aggregation of similar chromatophores on the yolk-sac, between the oil-globule and its posterior contour. In one specimen (diameter $\cdot 82 \mathrm{~mm}$.) the oil-globule, at this stage, has a dark and smoky appearance, and is densely pigmented. In another specimen no pigment is seen over the oil-globule, and the periblastic pellicle, which is generally quite apparent at this stage, showing an interspace between it and the contained oil-globule, is not distinguishable. The epidermis of embryo and yolk-sac is covered with tiny tubercles, doubtless of pathological origin. Next day the larva had hatched out but was distinctly moribund, and died almost immediately. The total length is $2.16 \mathrm{~mm}$., and it measures $1.00 \mathrm{~mm}$. from snout to anus. The head projects rather considerably over the oval-shaped yolk-sac. In two of my larvae the oil-globule was almost in the centre of the yolk-sac, which was observed by Heincke and Ehrenbaum to be the case only in one instance, and may be regarded, therefore, as an abnormal and possibly pathological condition. The small otocysts are situated some distance behind the eyes. There is a slight swelling in the tubular gut above the pectoral region and the rectum ends blindly immediately behind the postero-dorsal edge of the yolk-sac. The pigmentation, which is on a generous scale, is very characteristic. Inter-ramifying yellow chromatophores form a diffuse mass of colour over the posterior part of the yolk-sac, and practically over the whole of the pre-anal part of the trunk and head, extending a little beyond the anus. Then comes a clear space followed by a band of yellow somewhat behind the mid-postanal point. The much less conspicuous black pigment in small chromatophores which when relaxed show fine dendritic outgrowths, occurs chiefly on the dorsum in the pre-anal region and, less densely, on the head and sides. Post-anally there are about half a dozen chromatophores along each of the dorsal and ventral contours, extending further posteriorly than the yellow pigment, although the extreme end of the tail is pigmentless for about $\cdot 25 \mathrm{~mm}$. Black chromatophores are 
associated with yellow in the posterior hemisphere of the yolk-sac. The unpaired fins are pigmentless, except for a touch of yellow near the origin of the dorsal fin, immediately behind the otic region.

Apart from its peculiar colouring the larva has the unmistakable gadoid form. The dorsal fin membrane arises over the occipital region, reaches its greatest width above the anus, and thence tapers gradually to the caudal extremity; and similarly the greatest width of the anal fin is immediately below the anus.

On 2nd July, in a surface tow-netting $1 \frac{1}{4}$ miles N. by W. of the Eddystone, an egg was taken which may possibly be identified with this species. Its diameter was $.86 \mathrm{~mm}$, and its single oil-globule measured $18 \mathrm{~mm}$. The yolk was unsegmented. Just before the outgrowth of the caudal rudiment the body was abundantly besprinkled with faint dark chromatophores. The body appeared relatively wide. Next morning the larva showed a short caudal rudiment and much increase of pigment, which is now canary-yellow as well as black. Roundish chromatophores are fairly generally distributed over the anterior part of the body, but the black appears to be mostly dorsal and the yellow ventral. Post-anally the pigment is less dense. The pellicle of the oil-globule, which has a rough, wrinkled, and rather dark appearance, bears many rounded chromatophores of both colours, rather larger than those on the embryo and constitutes the most conspicuous feature of the ovum. There are a few fine, chiefly yellow chromatophores in the dorsal part of the yolk-sac. The otocysts are relatively small and the rudimentary pectoral fins appear as narrow flaps.

\section{Clupea sprattus. Sprat.}

This egg was the commonest of those belonging to food-fishes which occurred in my samples. It was found almost continuously from the middle of February to the middle of June, after which time until 12th July it appeared with less frequency; which may, however, be largely due to the fact that in the summer months most of my plankton was collected from the open sea, while the sprat appears to favour the close vicinity of Plymouth Sound or Cawsand Bay as a spawning locality in the warmer months; although not in winter and early spring. Very many eggs were taken in the young-fish trawl in June and July. The eggs, which are very characteristic from their segmented yolk, had an average diameter of $1.031 \mathrm{~mm}$. for February-March, $0.973 \mathrm{~mm}$. for April-May, and 0.912 for June-July. The pelagic larvae, which will be treated at greater length in a subsequent paper, were most abundant in May and June. 


\section{Clupea pilchardus. Pilchard.}

My first pilchard eggs were taken on 8th April, 7 miles S.W. of the Eddystone, when several occurred in the tow-nettings. The diameter ranged from $1.63 \mathrm{~mm}$. to $1.84 \mathrm{~mm}$., and that of the oilglobule from 0.15 to $0.16 \mathrm{~mm}$. The next specimen (of $1.6 \mathrm{~mm}$. and $0 \cdot 145 \mathrm{~mm}$. oil-globule) was found in a young-fish trawl haul taken near the Eddystone on 26th August. More surprising was the occurrence of three eggs in a tow-netting taken inside the Sound on the 14th September. These had diameters of $1.46,1.52$, and $1.62 \mathrm{~mm}$, and oilglobules of $0.145,0.155$, and 0.14 respectively. A newly hatched larva from one of them, measured after being killed in dilute formalin, had a length of $3.8 \mathrm{~mm}$. I may also mention that I have found numerous pilchard eggs in samples of plankton taken in the young-fish trawl in September, 1906, on the Rame-Eddystone Grounds.

As Cunningham (4a, p. 44, and 4d, p. 154) has pointed out, pilchards spawn far out at sea, and it is doubtless due to the fewness of my townet samples from the open-sea areas that such a small number of pilchard eggs have come under my observation this season. I may mention in passing that the pilchard fishery season in 1909 has been a decided failure in the Plymouth district as off the Cornish coast, the shoals having kept out in mid-Channel 20 miles or more from the coast, and therefore out of reach of the usual fishing craft. It should be remembered that the great majority of pilchards caught by Plymouth drifters are not spawning fish, the usual shoreward movement of this species in summer and early autumn being apparently a feeding migration. It is hardly relevant to the present subject to discuss the possible causes of the unusual distribution in 1909 , nor is there completely satisfactory evidence available. We may, however, assume that the distribution of the spawners which appear to lie outside the main summer shoals may show some variation in relation to the movements of the latter. My collections certainly sampled only the fringe of the great mass of ova spawned, or those which drifted landward with the tide and currents.

\section{B. DEMERSAL EGGS.}

\section{Labrus ? mixtus, L.}

Eggs which in all probability belong to Labrus mixtus were found deposited among a mass of Chondrus crispus in a rock-pool on Wembury Reef on 17th June. The mode of occurrence is very similar to what has been described by Matthews for Labrus maculatus (17), and my first idea was that this was the species to which the "nest" 
belonged, as it is the most common wrasse in the locality, which could with any certainty be regarded as the parent fish. The smaller size of the eggs, however, and certain differences exhibited by the hatched-out larvae, led me to conclude that this was not a species identical with that described by Matthews, though certainly a closely related form. Of the other wrasses (having unknown ova and larvae) which are known to occur here-Labrus mixtus, Crenilabrus melops, and Centrolabrus exoletus - the first is the form to which every probability points as the parent of these eggs. It is the one other species known to form a nest similar to that of $L$. maculatus (18, Vol. III, p. 102), and the size of the eggs is also most in agreement with this parentage. Ripe ova from Crenilabrus melops have been described by Holt (11a, p. 450) as spherical and having a diameter of $0.78 \mathrm{~mm}$. Crenilabrus exoletus, of whose eggs I have no knowledge, is an exceedingly small fish, and is not at all likely to produce ova as large as my specimens. It is moreover a more deep-water form, and is not known to construct a nest between tide-marks.

My specimens had a spherical or somewhat ovoid shape and a thick strong capsule. Five which were measured had the following dimensions-0.92, $0.94,0.94,0.90 \times 0.94$ and $1.08 \times 0.86 \mathrm{~mm}$. When first observed on the 17 th June the embryonic body with well-marked myomeres had formed, but no caudal outgrowth had appeared. There was a large Küpfer's vesicle. No pigment was visible. The yolk was pale buffcoloured and devoid of any oil-globule. Four days later they have reached the final stage of embryonic development (Fig. 4). The yolk is much reduced, its diameter being about four-sevenths that of the egg-capsule, and the caudal extremity has grown around so that its tip in some cases overlies the auditory region. The yolk is ochreous-yellow and shows a number of small vesicles in the mid-ventral part. In the eyes there is black pigment through which shine golden tints. The body is bestrewn with black chromatophores for about two-thirds of its length, and posterior to this there are some along the dorsal and ventral contours, but the posterior extremity is unpigmented. Yellow chromatophores occur on the anterior part of the body. The yolk-sac shows a few round black pigment spots and many yellow ones. The pectoral fins appear as semicircular flaps near the posterior edge of the yolksac. Small bean-shaped otocysts occur at a distance behind the eyes about equal to the diameter of the lens. Fig. 8 depicts a slightly earlier stage.

Two larvae (Fig. 8) measured within a few hours of hatching were 3.26 and $3.28 \mathrm{~mm}$, in length, the pre-anal lengths being 1.80 and $1.76 \mathrm{~mm}$. respectively. The yolk-sac is relatively small, and its con- 
tents are clear and almost colourless. The head is rounded; the anus post-median. The dorsal fin membrane arises above the mid-brain and is widest above the anus. There is a well-marked pre-anal fin. The whole of the larval fin membrane has a minute vesicular structure, which is probably a mark of ill-health. Embryonic rays can be seen in the caudal region. The notochord has two layers of cells at least in its posterior part. The pectoral fins are well developed. The body is richly pigmented with black and yellow chromatophores, but the posterior third is conspicuously bare, except for a line of black chromatophores along the ventral contour, while black pigment is lacking above the mid-brain. The sides of the body from the occipital region to a short distance beyond the anus are almost uniformly coloured with round, stellate, black chromatophores about four or five deep. These are most closely set along the dorsal contour, and are more densely distributed above and posterior to the anus than above the yolk-sac. They are not uniformly distributed in the body segments as described by Matthews for $L$. maculatus, but except for the posterior continuation of the ventral line, as above-mentioned, and for the presence of black chromatophores over the sides of the gut, the distribution and abundance of black pigment on the body show much agreement with his specimen. The largest black chromatophores of all are to be seen on the yolk-sac. A group of about five to eight large, but not very intense, chromatophores occurs in the anal fin, immediately behind the anus; otherwise, except for outgrowths from pigment cells along the posterior ventral body margin, the larval fin membranes are entirely free from black pigment (see Figs. 8 and 8a). Yellow pigment is regularly interspersed with black along the sides of the trunk, but is absent over the sides of the gut. There are a few yellow chromatophores on the head, and a single isolated one near the margin of the anal fin, about half-way between the anus and the posterior end of the notochord. . Another specimen which I examined showed a less uniform distribution of black pigment on the side of the trunk in the pre-anal region, the chromatophores tending to concentrate along the dorsal contour and above the gut. On the second day the larva had a length of $3.48 \mathrm{~mm}$., the increase being practically entirely post-anal. At this point I made detailed measurements, so as to compare with Matthews' dimensions for $L$. maculatus, which I give side by side below :-

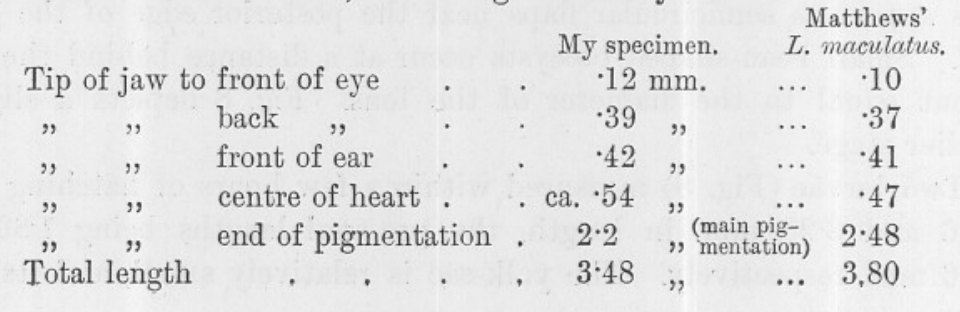


I also noted that my larva was distinctly more slender in dorsal view than Matthews' L. maculatus (op. cit., Pl. XI).

The pigmentation is in general the same on the second day as on the first, but the post-anal pigment in the anal fin has slightly increased. With the total absorption of the yolk, which has taken place on the fourth day, a still further increase of this pigment is seen, the group of chromatophores behind the anus now numbering fourteen or fifteen; and there is a further extension of pigment from the ventral edge of the trunk to the proximal margin of the anal and pre-anal fin membranes. The embryonic fin-rays, in both the dorsal and ventral parts of the caudal region of the larval fin membrane, are now very evident. A specimen at this stage, after killing in dilute formalin, measured $3.5 \mathrm{~mm}$.

Blennius pholis, L. The Shanny.

It is somewhat surprising that the earliest stages of this common blenny should have remained unknown for so long. McIntosh (14g) has published some observations upon eggs deposited in captivity. These were circular in outline, oblate spheroidal in lateral view, and each had a faintly pinkish attachment disc. The diameter was $1 \cdot 181$ to $1.219 \mathrm{~mm}$., the vertical diameter being 0.763 and the height of the attachment rim $0.305 \mathrm{~mm}$. He describes the yolk colour as dull pinkish or faint salmon and in certain lights having a dull brownish appearance.

On June 4th some eggs of Blennius pholis accompanied by the parent fish were taken on a stone on the Breakwater rocks. In shape they were ovoid with flattened underside (Fig. 3). The length of the capsule was $1.6 \mathrm{~mm}$., the vertical height just above $1 \mathrm{~mm}$. (with the attachment disc ca. $1.4 \mathrm{~mm}$.). When observed they were at the last stage of embryonic development, the black eyes of the embryo rendering them very conspicuous. The yolk was of a light brown colour. The newly hatched larva (Fig. 6) is of large size-about $4.4 \mathrm{~mm}$. total length and $1.8 \mathrm{~mm}$. from snout to anus. Its very broad and somewhat square head gives it a tadpole-like appearance. There is a striking absence of post-anal pigment. A most conspicuous feature is the pair of large fan-like and heavily pigmented pectoral fins. These are marked with large, black and yellowish brown chromatophores, the former disposed in radial lines, the latter being most concentrated in the basal region and absent from the distal margin. Other black pigment occurs in the eyes, under the mandible where three stellate chromatophores are disposed symmetrically in triangular form, on the neck region as a single pigment spot, and in the peritoneum where there is a short double row of chromatophores. The yolk-sac, pro- 
truding on each side, has a yellowish brown tint; there are pale yellow chromatophores on the head and similar pigment, but of more intensity, in the pectoral region. The thickness and opacity of the head causes the otocysts to be hardly visible. The course of the red blood corpuscles along the circulatory system from the yolk to the body of the larva can be very easily seen.

\section{Gobius paganellus, Gm. L.}

Some eggs, together with a fish of this species, were taken on a stone between tide-marks on the shore of Rum Bay on 3rd June. The ova have been described by Holt and Byrne (13, p. 46) as regularly fusiform in shape, about twice as high as wide and with rather sharply pointed ends; by which characters they are distinguishable from the eggs of all other British species of goby. The above-mentioned authors give 1.84 to $1.9 \mathrm{~mm}$. as the length. An egg which I measured at a late embryo stage was $2.3 \mathrm{~mm}$. long and $0.74 \mathrm{~mm}$. wide, while a second was slightly longer. The yolk was of a greyish brown colour and was darkened by the presence of many small oil-globules. When the embryo is advanced in development, the eyes become extremely conspicuous, showing abundant black pigment and a bronze-green lustre. The oval swim-bladder with strongly marked dendritic chromatophores and some yellow pigment over the dorsal side of it is plainly visible. This is the only really conspicuous pigment on the embryo at this stage. The large bean-shaped otocysts contain relatively small otoliths.

The newly hatched larva (Fig. 7) has a total length of $4.8 \mathrm{~mm}$., the pre-anal length being $2 \cdot 2 \mathrm{~mm}$., so that the anus is just anterior to the median. The head is somewhat rounded and the lower jaw slightly projecting. The large, oval swim-bladder is a conspicuous object midway between otocysts and anus. The gut is straight and has a slight ventral dilation below the hinder end of the swim-bladder. As in the embryo, the most conspicuous pigment is above the swim-bladder (black and yellow) and in the eyes, which are black with blue, green, and gold tints. There is a continuous row of black chromatophores from the throat to the anus along the ventral contour, the largest one with well-marked dendritic rays being below the above-mentioned bulge in the gut; the terminal one below the anus is also very pronounced. Except above the swim-bladder there is no peritoneal pigment nor any other chromatophores anterior to the anus. Post-anal ventral pigment consists of a discontinuous series of black dendritic chromatophores (about six or less in number) extending to the hypural region, the largest of which is situated in the centre of the post-anal 
part and has yellow associated with it. Dorsally there is only one, relatively small, black chromatophore, accompanied by yellow, opposite the large mid-post-anal one of the ventral row. This dorsal pigment is often lacking entirely. The notochord is unicolumnar. The pectoral fins are rather large, extending to about the middle of the swimbladder. The embryonic dorsal fin arises above their base. There is a short pre-anal fin commencing below the gastric dilation. A brownish gall-bladder is visible. At the age of five or six days the ventral post-anal pigment appears to have concentrated itself more in the central part of the post-anal region and in the hypural part, but otherwise the pigment remains as in the early stages. Embryonic finrays have developed in the position of the second dorsal and the anal fin and a hypural lobe has formed.

\section{Lepadogaster bimaculatus, Donov. Doubly spotted Sucker.}

The eggs and newly hatched larva of this species have previously been described by Holt (11a, p. 447, Pl. XLVII, Figs. 1 to 7), but as all my observations have shown certain differences from the specimens he describes it will be well to give some details from my records.

My observations were first undertaken chiefly with a view to getting a knowledge of the early post-larval forms for the purpose of comparison with pelagic Lepadogaster fry taken in our young-fish trawl. The following are brief particulars as to the capture of specimens of the eggs of this species which came under my notice in the summer of 1909 :-

\begin{tabular}{|c|c|c|c|}
\hline Date. & Locality. & $\begin{array}{l}\text { Instrument of } \\
\text { capture. }\end{array}$ & Other remarks, \\
\hline 8th June, 1909 & Queen's Ground. & Dredge . & $\begin{array}{l}\text { Eggs encrusting inside of a Tellina } \\
\text { valve. Greatest horizontal axes } \\
\text { of egg-capsule, } 1.4 \times 1.2 \mathrm{~mm} \text {. }\end{array}$ \\
\hline 16th June, 1909 & $\begin{array}{l}\text { Rame-Eddystone } \\
\text { Ground }\end{array}$ & Otter trawl & $\begin{array}{l}\text { Eggs in Lutraria valve with } \\
\text { parent fish. Greatest horizontal } \\
\text { dimensions, } 1.4 \times 1.16 \mathrm{~mm} \text {; } \\
\text { height, } 0.70 \mathrm{~mm} \text {. }\end{array}$ \\
\hline 5th July, 1909 & Hand Deeps & Dredge . & $\begin{array}{l}\text { Several batches of eggs with } \\
\text { parent fish in valves of Pecten } \\
\text { opercularis and Lutraria. }\end{array}$ \\
\hline 13th July, 1909 & Hand Deeps & Dredge . & $\begin{array}{l}\text { Eggs in Pecten opercularis valve. } \\
\text { Accompanying fish a female. }\end{array}$ \\
\hline
\end{tabular}

On 14th. June a female Lepadogaster bimaculatus, with spent, flaccid and membranous ovaries, was taken in a Lutraria valve, within which a batch of eggs had been deposited, but which had disappeared, leaving traces of their former presence in the form of oval impressions. The

NEW SERIES.-VOL. IX. No. 1. OCTOBER, 1910. 
nudibranch Calma glaucoides and a batch of its eggs were also occupying the valve, and it seems probable, if not certain, that the fish-eggs had been devoured by the nudibranch, which has been recorded as commonly occurring associated with Goby and Blenny eggs, and varying in colour so as to resemble the eggs which it apparently preys upon.*

Quite recently-viz. on 17th February, 1910, and after this paper was in manuscript-I have secured an early batch of Lepadogaster bimaculatus eggs. On this occasion I took particular care to examine the accompanying parent fish so as to make sure of its identity as distinct from $L$. microcephalus, a closely similar species first distinguished by Brook, $\uparrow$ whose description, however, I have not yet been able to see. Ehrenbaum (5b, p. 121) gives as the distinctive fin-ray formula for $L$. microcephalus $\mathrm{D}=5, \mathrm{~A}=6, \mathrm{C}=17-19$; while Day gives for $L$. bimaculatus $\mathrm{D}=5-7, \mathrm{~A}=4-6, \mathrm{C}=12$. My specimen has clearly six dorsal fin-rays and not more than four or five anal fin-rays, which precludes $L$. microcephalus, while in its general appearance it resembled the common two-spotted sucker, $L$. bimaculatus. It was not possible to count the caudal rays, as it was desired to keep the specimen alive and uninjured. Two of the eggs had the following dimensions :-Oval outline of egg-capsule, as seen from above, measured in one case $1.44 \times 1.24 \mathrm{~mm}$. and in the other $1.54 \times 1.22 \mathrm{~mm}$. The height of the capsule was respectively 0.62 and $0.70 \mathrm{~mm}$. The sizes closely approximate to those noted the previous summer, and in following through the development from pre-embryonic to larval stages, the characters proved to be identical, save for very slight variation in pigmentation.

The ovoidal inferiorly truncated egg-capsule and its peculiar basal attachment disc and filaments have been minutely described by Holt (op.cit.). I noted that as a rule the eggs in one batch showed several stages of development, indicating that they were deposited intermittently. In the earliest stages the finely granular yolk is quite colourless and translucent, and carries a single oil-globule of about 0.25 to $0.28 \mathrm{~mm}$. diameter, which has a slightly darker appearance than the yolk and is at first the most conspicuous content of the egg. The embryo almost invariably occupies a horizontal position in the egg. Black pigment appears on the body soon after the outgrowth of the caudal rudiment, and soon forms a dense and continuous line along the ventro-lateral region from immediately behind the pectoral fins to within a short distance of the caudal tip. Anteriorly pigment is sparse, only a few

* See Journ. M.B.A., N.S., Vol. VII, p. 280.

† Brook, G., Proc. Roy. Phys. Soc. Edin., Vol. X, Pt. 1, p. 166. 
chromatophores occurring about the neck region and shortly afterwards on the eyes. Yellow chromatophores (bright lemon-yellow by reflected light, brownish by transmitted light) next appear on the sides of the embryo above the dense line of black pigment above-mentioned (see Fig. 5). At about the same time black chromatophores frequently appear along the dorsal surface of the yolk-sac adjacent to the trunk of the embryo. The circulatory fluid is now of a red colour, which is plainly visible at the heart systole. Before the appearance of the yellow pigment the blood was colourless, but even then its circulation could be observed in vessels from the yolk-sac, and in the aorta and main arteries of the head. A day or two after the appearance of yellow, an increase takes place in the amount of black pigment, a double ventro-lateral line being formed on each side with the inferior pair, which are the more distinctly marked, coming together at the anus. A sprinkling of lateral chromatophores next appears, and the eyes become so dark as to be conspicuous to the naked eye. The only other black pigment in the anterior region is a pair of lines converging towards the occiput from the posterior lateral part of the yolk-sac. The yolk-sac and occipital region are covered with diffuse pale yellow.

The newly hatched larva (see Fig. 16) has a length of $4.26 \mathrm{~mm}$., of which about five-eighths is pre-anal. The remnant of yolk is relatively small, as is usual with larvae from demersal eggs, and bulges out on each side of the larva. A small oval swim-bladder is present. Rounded, stellate, black chromatophores uniformly beset the sides of the trunk in fairly regular lines, which are about four deep transversely in the pre-anal and about three deep in the post-anal region. These are larger in the anterior part of the body than posteriorly. There are similar lines of yellow chromatophores (pale lemon coloured by reflected, brownish by transmitted light) slightly less numerous and at greater interval. These are more densely distributed posteriorly than anteriorly. The most dorsal row of chromatophores are yellow and these are of a larger size and greater denseness than the others. Over the straight intestine yellow pigment is generally sparse and sometimes quite lacking. The posterior portion of the tail, for about $1 \mathrm{~mm}$., is quite unpigmented, as is also the median strip along the whole dorsum. The only pigment in the larval fins consists of a small group of about three to five black chromatophores in the anal fin immediately behind the anus. The snout is rounded. The large otocysts are situated immediately behind the eyes. The dorsal fin arises a little behind the level of the posterior edge of the yolk-sac. Tiny epidermal vesicles densely cover the embryonic fins, except along the margin of its most posterior part. 
Two post-larvae, measured soon after the yolk had been absorbed, had lengths of 4.8 and $4.9 \mathrm{~mm}$. The jaws had appreciably developed, especially the mandible, so that the earlier sub-terminal position of the mouth was changed; but otherwise they resembled the newly hatched individuals. The differences between my specimens and those recorded by Holt are in size and pigmentation. His newly hatched larvae measured 2.97 to $3.15 \mathrm{~mm}$., and apparently had no yellow pigment (op. cit., p. 448). His eggs were slightly smaller than mine, having a length of $1.37 \mathrm{~mm}$, a breadth of $1.08 \mathrm{~mm}$, and a height of $0.68 \mathrm{~mm}$., and the oil-globule measured $0.24 \mathrm{~mm}$. Guitel (9, Pl. XXV, Fig. 8) figures an early post-larval $L$. bimaculatus of uncertain age, which is about $4.6 \mathrm{~mm}$. long and is pigmented somewhat similarly to those I have examined, except that the superior line of yellow chromatophores is not clearly shown on the side and the black chromatophores are lacking in the anal fin. As regards Holt's specimen, if it is the same species as those I have examined, I can only suggest that it may have been an abnormal specimen, possibly prematurely hatched under unfavourable conditions.

\section{Lepadogaster gouani, Lacep. Cornish Sucker.}

On the 17th June several batches of the eggs of this species were taken on the underside of flat stones between tide-marks on Wembury Reef. The parent fish was always to be found near, and generally close alongside the eggs, which cover several square inches of the stone with a closely applied layer. Two, three, or four stages of development may be seen in one batch of eggs. In the earliest stages the yolk is bright amber coloured, which renders the mass of ova an object of much conspicuousness and beauty. Subsequently the colours become gradually darker to orange, and finally, when the embryo is advanced, they have in the mass an olive-green appearance. The eggcapsule is oval-shaped with flattened base, of length $1.90 \mathrm{~mm}$. and breadth $1.56 \mathrm{~mm}$. The yolk contains a large oil-globule of $0.34 \mathrm{~mm}$. diameter.

When a short caudal rudiment is developed, the embryo has a general reddish tint, and shows many stellate black chromatophores over the greater part of the body, the posterior portion, however, being unpigmented. The movement of pale reddish circulatory fluid along the vessels from the yolk to the heart is plainly visible.

The newly hatched larva has a length of $5 \cdot 1 \mathrm{~mm}$, the anus is post-median, and the yellowish yolk-sac protrudes on either side of the anterior abdominal region. The straight gut shows internal convolutions and a yellowish green gall-bladder is visible. The dorsal 
embryonic fin arises in the occipital region, the caudal part of it being spatulate. The head is rounded and the mouth terminal, the otocysts situated immediately behind the eyes. Pigmentation is extremely rich. Black chromatophores are the most abundant, covering the sides of the trunk and gut in closely set and fairly regular longitudinal lines. The largest chromatophores are those on the dorsal surface of the head, and those along the dorsal contour are the largest and most closely set of those on the trunk. Post-anally the number of chromatophores counted transversely is four or five. About $0.8 \mathrm{~mm}$. from the posterior end of the notochord, the greater part of the pigmentation ceases, but there may be a few small pigment spots over the notochord behind this point. Along the anal fin there is a line of black chromatophores, extending from immediately behind the anus to the hypural area. Mid-laterally, where the black pigment is least dense, there is an irregular line of about seven large lemon-yellow chromatophores, extending from the level of the posterior edge of the yolk-sac to a little behind the anus. Between all the other chromatophores are numerous small orange-coloured ones, with a relatively. large, clear, central space, which gives them the appearance of small rings. Most of the black and yellow chromatophores also have the form of radiations from a central unpigmented spot. Small, round or stellate chromatophores of a pure red colour occur on the ventral surface of the abdomen anterior to the anus. There is no yellow or orange pigment over the sides of the abdomen, but only black, and it is perhaps worthy of note to mention that the black chromatophores of this region appear to have a different structure from those over the rest of the body, the centre of the spot in this case being pigmented instead of clear. The proximal part of the median fin membrane shows the same minute vesicular structure as was seen in $L$. bimaculatus, but the vesiculation does not extend so near to the margin.

A slightly older larva measured $5.7 \mathrm{~mm}$., and was $3.2 \mathrm{~mm}$. from snout to anus. At four or five days old the length is $6.3 \mathrm{~mm}$., the pre-anal portion being $3.4 \mathrm{~mm}$. A hypural thickening is visible. The pigmentation at this age is practically the same as in the newly hatched form, except for an increase of red pigment on the inferior parts of the body. A larva in which the yolk has been entirely absorbed shows small red chromatophores on the ventral surface of the lower jaw, on the ventrolateral part of the opercular region, on the ventral and ventro-lateral surface of the abdomen and over the basal part of the large pectoral fins.

The pelagic post-larval stages of $L$.gouani can be easily distinguished from those of $L$. bimaculatus by their larger size at the same point in 
development, and by the distinctiveness of their coloured pigment. In preserved specimens in which all but the black chromatophores have disappeared, one can at once distinguish $L$. bimaculatus by its relatively wide unpigmented strip along the dorsum, only a very narrow line being left clear between the pair of dorsal lines of chromatophores in $L$. gouani. There is also a difference in the distribution of pigment spots in the anal fin. As is to be expected, however, I have never met with the young stages of $L$. gouani in plankton taken away from the vicinity of the shore, while post-larval $L$. bimaculatus may be taken some miles out at sea.

\section{Zeus faber, L. John Dory.}

On 31st August five good-sized dories were taken in the otter-trawl $2 \frac{1}{2}$ miles S.W. of Rame Head. One of these was an unripe male, and three were females, which had recently spawned. From the ovary of one of the latter I obtained a dead egg, which had already undergone degeneration and was opaque and pale greenish in colour. The fifth proved to be a female approaching ripeness, and from the ovary of this I obtained a few apparently ripe eggs, which occurred free in the lumen. The great majority of the ova, however, were still small and opaque, and contained firmly in the ovigerous lamellae. The ripe eggs are large and contain a relatively small greenish yellow oil-globule (Fig. 1). The rather thick egg-capsule is marked by conspicuous corrugations, which appear to be intertwined in a very irregular manner, and also by finer striations, the former of which are doubtless merely characteristic of the ovarian condition and caused by contact with vascular tissue in the ovary. The yolk is colourless and homogeneous, the ripe egg being translucent and glassy, but not of that clear transparency which is seen in all pelagic eggs, and by transmitted light it has a slightly brownish tint, which is apparently produced by the interference of the corrugated capsule with the free transmission of light rays.

The dimensions taken from four eggs are as follows :-

\begin{tabular}{cccc}
\multicolumn{2}{r}{ Diameter of Egg. } & \multicolumn{2}{c}{ Diameter of Oil-globule. } \\
(1) $2.04 \times 2.14 \mathrm{~mm}$. & $\ldots$ & $0.44 \mathrm{~mm}$. \\
(2) 2.03 & $\#$ & $\ldots$ & 0.44, \\
(3) 2.05 & $"$ & $\ldots$ & 0.28 and $0.22 \mathrm{~mm}$. \\
(4) 1.90 & $\#$ & $\ldots$ & $0.43 \mathrm{~mm}$.
\end{tabular}

In the third egg measured the oil was contained in two separate globules, which is commonly the case in an unfertilized egg. The fourth specimen measured was apparently not quite ripe.

The eggs sink in sea-water of specific gravity 1.026. Fulton (8), from 
minute observations made upon the ripening ovarian ova of a dory caught in April, concluded that the mature eggs would prove to be large, contain one or more oil-globules and be demersal; which conclusions are confirmed by the character of my ripe eggs. Their demersal nature was indicated, even at that stage, by the comparatively dense fibrous nature of the tissue of the stroma and the follicle, by the presence of a well-defined double layer, by the character of the yolk, and by the general hardness and resistance to pressure, all these features being in contrast with ovarian pelagic eggs. One of the largest specimens examined by Fulton from the ovarian stroma measured $1.39 \mathrm{~mm}$. in diameter and contained two groups of three and four oil-globules. Some other slightly smaller eggs contained a prominent straw-coloured oil-globule: thus in an egg of $1.02 \mathrm{~mm}$. diameter the oil-globule measured $0.25 \mathrm{~mm}$. All these were quite opaque and white by reflected light and still contained in the follicular investment.

Holt has recorded the capture of ripe females off the west coast of Ireland in July and August, and one spent in June.* Cunningham (4g, p. 322) also has found ripe females in August at Plymouth. The demersal character of the eggs and the relatively deep-water habitat of the spawning fishes are sufficient to account for the present lack of knowledge of embryonic development. The youngest post-larval stages yet recorded are those described by Schmidt (21d) from four specimens ( $7 \frac{3}{4} \mathrm{~mm}$. to $19 \mathrm{~mm}$. long) taken by the Thor in August and September, 1906 (three from various parts of the Channel and one from the Bay of Biscay); to which must be added one specimen of $14 \mathrm{~mm}$. taken by the Oithona's young-fish trawl off Plymouth Sound on the 17th of September in the same year.

\section{BIBLIOGRAPHY.}

1. Brook, G.-a. Preliminary Account of the Development of Lesser Weever (Trachinus vipera). Linn. Soc. Journ. Zool., XVIII (1884), pp. 27491, Pl. III-VI.

b. On Some Points in the Development of Motella mustela. Ibid,, pp. 298-306, Pl. VIII-X.

2. Browne, F. Balfour.-Report on the Eggs and Larvae of Teleostean Fishes observed at Plymouth in the Spring of 1902. Journ. Mar. Biol. Assoc., N.S., Vol, VI (1903), pp. 598-616.

3. Canu, E,-a. Ponte, œufs et larves des poissons utiles observés dans la Manche. Annales de la Stat. Aquic. de Boulogne, Vol. I (1893), pp. 117-32, Pl. VIII-XV.

b. Ibid., Vol. II (1894), pp. 63-72, Pl. I-V.

* Report of the Council Royal Dublin Society, 1892, p. 245. 
4. Cunningham, J. T.-a. Studies on the Reproduction and Development of Teleostean Fishes occurring in the Neighbourhood of Plymouth. Journ. Mar. Biol. Assoc., N.S., Vol. I (1889-90), pp. 10-54, Pl. I-VI.

b. A Treatise on the Common Sole. Plymouth (1890).

c. On Some Larval Stages of Fishes. Journ. Mar. Biol. Assoc., N.S., Vol. II (1891-2), pp. 68-74, Pl. III-IV.

d. The Reproduction and Growth of the Pilchard. Ibid., pp. 154-7, Pl. X.

e. The Egg and Larva of Callionymus lyra. Ibid., pp. 89-90, Pl. V.

f. The Life History of the Pilchard. Ibid., N.S., Vol. III, pp. 14853.

g. Natural History of Marketable Marine Fishes of the British Isles. London (1896).

5. Ehrenbaum, E.-a. Eier und Larven von Fischen der deutschen Bucht. I. Wissensch. Meeresuntersuchungen, Abt. Helgoland, II (1897), pp. 253328, Taf. III-VI.

b. Eier und Larven von Fischen, 1 Teil. Nordisches Plankton (1905).

c. Ueber Eier und Jugendformen der Seezunge und anderer im Fruhjahr laichender Fische der Nordsee. Wissensch. Meeresuntersuchungen, Abt. Helgoland, VIII (1907), pp. 201-70.

d. Eier und Larven von Fischen, 2 Teil. Nordisches Plankton (1909).

6. Ehrenbaum, E., and S. Strodtman.-Eier und Jugendformen der Ostseefische. Wissensch. Meeresuntersuchungen, Abt. Helgoland, VI (1904), pp. 57-126.

7. Fabre-Domergue et E. Biétrix.-Développement de la Sole. Paris (1905).

8. Fulton, T. Wemyss.-The Ovaries and Ovarian Eggs of the Angler (Lophius piscatorius) and of the John Dory (Zeus faber). Sixteenth Anmual Rept. Fish. Bd. Scotl. (1898), pp. 131-4, Pl. III.

9. Guitel, Fr.-Recherches sur les Lepadogasters. Arch. de Zool. experim., 2 S., Vol. VI (1888), pp. 576-94, Pl. XXXIII-XXXV.

10. Heincke, Fr., and E. Ehrenbaum.-Eier und Larven von Fischen der Deutschen Bucht. II. Die Bestimmung der schwimmenden Fischeier und die Methodik der Eimessungen. Wissensch. Meeresunters. Abt. Helgoland, III (1899), pp. 131-332, Taf. IX-X.

11. Holt, E. W. L.-a. Survey of Fishing Grounds, West Coast of Freland, 1890, I. On the Eggs and Larvae of Teleosteans. Sci. Trans. Roy. Dubl. Soc, Vol. IV, S. II (1891), pp. 435-74, Pl. XLVIII-LII.

b. Survey of Fishing Grounds, West Coast of Ireland, II, 18901901. On the Eggs and Larval and Post-larval Stages of Teleosteans. Ibid., Vol. V., S. II (1893), pp. 5-121, Pl. I-XV.

c. Preliminary Notes on the Reproduction of Teleostean Fishes in the South-Western District. Journ. Mar. Biol. Assoc., N.S., Vol. V (1897), pp. 41-50.

d. Notes on the Reproduction of Teleostean Fishes in the South Western District. Ibid., pp. 107-55 and 333-40 (1897). 
e. On the Breeding of the Dragonet (Callionymus lyra). Proc. Zool. Soc. (1898), pp. 281-315, Pl. XXVI.

f. Recherches sur la Reproduction des Poissons Osseu x. Annale du Musée d'histoire naturelle de Marseille. Zoologie, Tome V, No. 2 (1899), pp. 1-128, Pl. I-IX.

12. Holt, E. W. L., and Scott, S. D.-A Record of the Teleostean Eggs and Larvae observed at Plymouth in 1897. Journ. Mar. Biol. Assoc., N.S., Vol. V. (1897-9), pp. 156-71.

13. Holt, E. W. L., and Byrne, L. W.-British and Irish Gobies. Report Fisheries Irel. (1901), pp. 37-66, Pl. I and II.

14. McIntosh, W. C.- a. Further Observations on the Life History and Development of the Food and other Fishes. 9th Annual Rept. Fish. Bd. Scotl. (1891), pp. 317-34, Pl. X-XIII.

b. Contributions to the Life History of the Food and other Fishes. Ibid., 10th Rept. (1892), pp. 273-322, Pl. XIV, XVI.

c. Ibid., 11th Report (1893), pp. 239-49, Pl. VIII-XII.

d. Ibid., 12th Report (1894), pp. 218-30, Pl. II-IV.

e. Ibid., 14th Report (1896), pp. 171-85, Pl. V.

f. Tbid., 15th Report (1897), pp. 194-211, Pl. V-VII.

g. On the Life History of the Shanny (Blennius pholis, L.). Zeitsch. f. wissensch. Zool. 82.(1905), pp. 368-78, Pl. XXI.

15. McIntosh, W. C., and Masterman, A. T.-The Life Histories of the British Marine Food Fishes. London (1897).

16. McIntosh, W. C., and Prince, E. E.-On the Development and Life Histories of the Teleostean Food and other Fishes. Trans. Roy. Soc. Edin., Vol. XXXV, Pt. III (1890), pp. 665-946, Pl. I-XXVIII.

17. Matthews, J. Duncan.-Note on the Ova, Fry, and Nest of the Ballan Wrasse. 5th Ann. Rept. Fish. Bd. Scotl., p. 245, Pl. XI.

18. Moreau, Emile.-Histoire Naturelle des Poissons de la France. Paris (1881).

19. Petersen, C. G. Joh.-On the Eggs and Breeding of our Gobiidae. Report of the Danish Biological Station, II. (1891), pp. 1-9, Pl. I, a-1 b.

20. Raffaele, F.-Le uova galleggianti e le larve dei Teleostei nel golfo di Napoli. Mitteil. Zool. Sta. Neapel., VIII (1888), pp. 1-84, Tav. 1-5.

21. Schmidt, Johs.-a. The Pelagic Post-larval Stages of the Atlantic Species of Gadus, Pt. I. Meddelels. fra Komm. for Havundersog. Serie Fiskeri, Bd. I (1905), No. 4, Pl. I-III.

b. Idem., Pt. II. Ibid., Bd. II. (1906), No. 2, Pl. I.

c. Marking Experiments on Plaice and Cod in Icelandic Waters. Ibid., Bd. II (1907), No. 6.

d. On the Post-larval Stages of the John Dory (Zeus faber, L.) and some other Acanthopterygian Fishes. Ibid., Bd. II (1908), No. 9, Pl. I. 


\section{EXPLANATION OF PLATES I AND II,}

Illustrating Mr. A. E. Hefford's "Notes on Teleostean Ova and Larvae observed at Plymouth in Spring and Summer, 1909."

Plate I.

Fig. 1. Zeus faber, ripe ovarian egg; diameter, ca. $2.09 \mathrm{~mm}$.

Fig. 2. Zeugopterus punctatus, pelagic egg; diameter, $0.99 \mathrm{~mm}$.

Fig. 3. Egg of Blennius pholis, lateral view; dimensions, $1.8 \times 1.2 \times 0.8 \mathrm{~mm}$.

Fig. 4. Egg of Labrus mixtus; diameter, $0.94 \mathrm{~mm}$.

Fig. 5. Egg of Lepadogaster bimaculatus; dimensions, 1.44 ×1.24 $\times 0.62 \mathrm{~mm}$.

Fig. 6. Blennius pholis, newly hatched larva; length, ca. $4 \cdot 4 \mathrm{~mm}$.

Fig. 7. Gobius paganellus, newly hatched larva; length, $4.8 \mathrm{~mm}$.

Fig. 8. Labrus mixtus, newly hatched larva; length, $3 \cdot 26 \mathrm{~mm}$.

Fig. 8a. Labrus mixtus, sketch showing arrangement of anterior dorsal black pigment.

Fig. 9. Zeugopterus punctatus, newly hatched larva ; length $2.90 \mathrm{~mm}$.

Fig. 10. Z. punctatus, larva ca. 3 days old.

\section{Plate II.}

Fig. 11. Solea lascaris, newly hatched larva; length, $3.46 \mathrm{~mm}$.

Fig. 12. S. lascaris, larva 4 or 5 days old.

Fig. 13. Serranus cabrilla, early larva; length, $2: 30 \mathrm{~mm}$.

Fig. 14. Onos? tricirratus, Bl., newly hatched larva ; length, $2 \cdot 32 \mathrm{~mm}$.

Fig. 15. "Onos, species B" (? or abnormal form), newly hatched larva; length, $1.84 \mathrm{~mm}$.

Fig. 16. Lepadogaster bimaculatus, newly hatched larva ; length, $4 \cdot 26 \mathrm{~mm}$. 
Journ. Mar. Biol. Assoc. Vol. IX.

Plate I

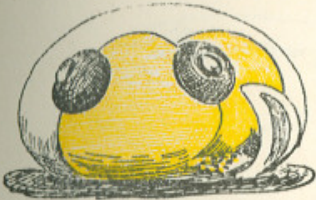

3
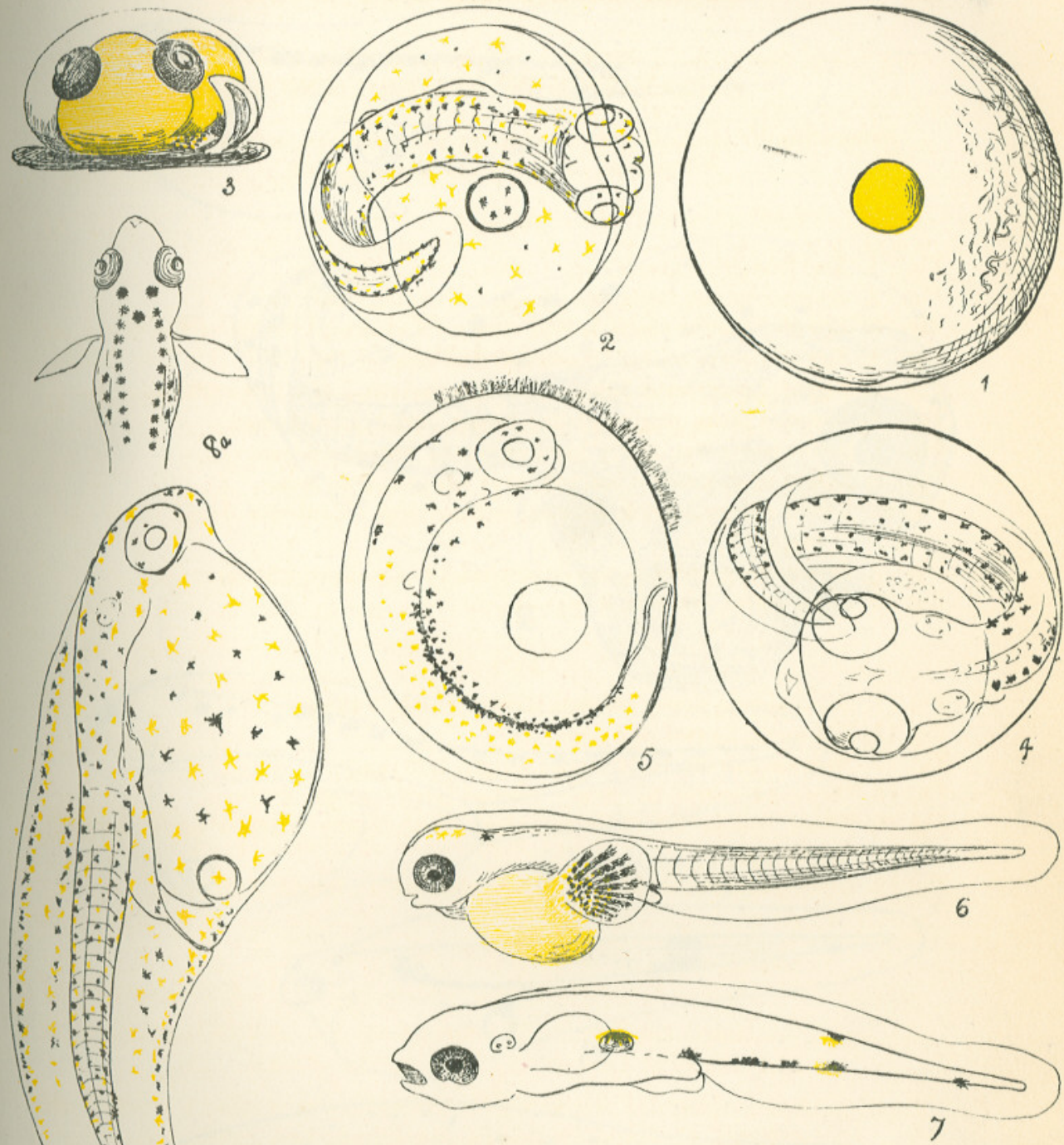

9

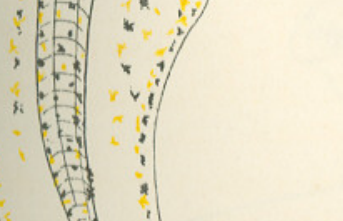

9

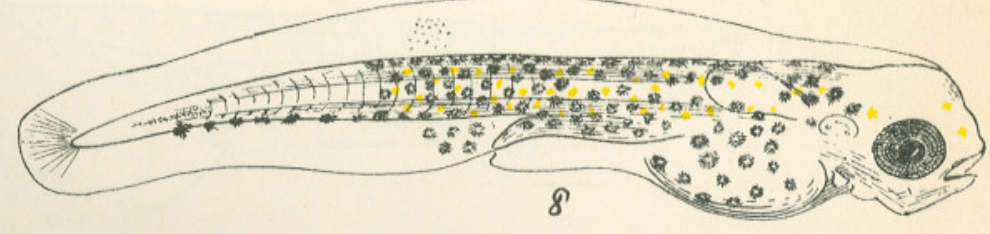

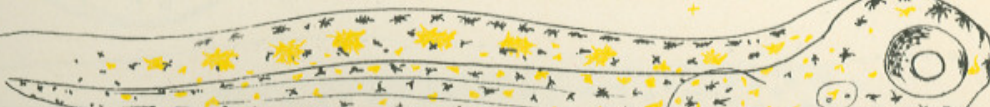

(6) -+

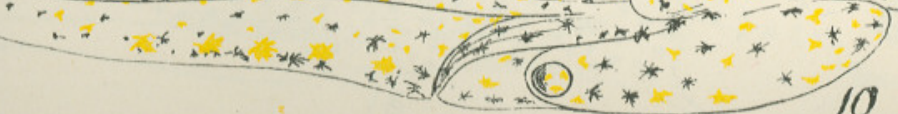

A. E. H. del. 
Journ. Mar. Biol. Assoc. Vol. IX.
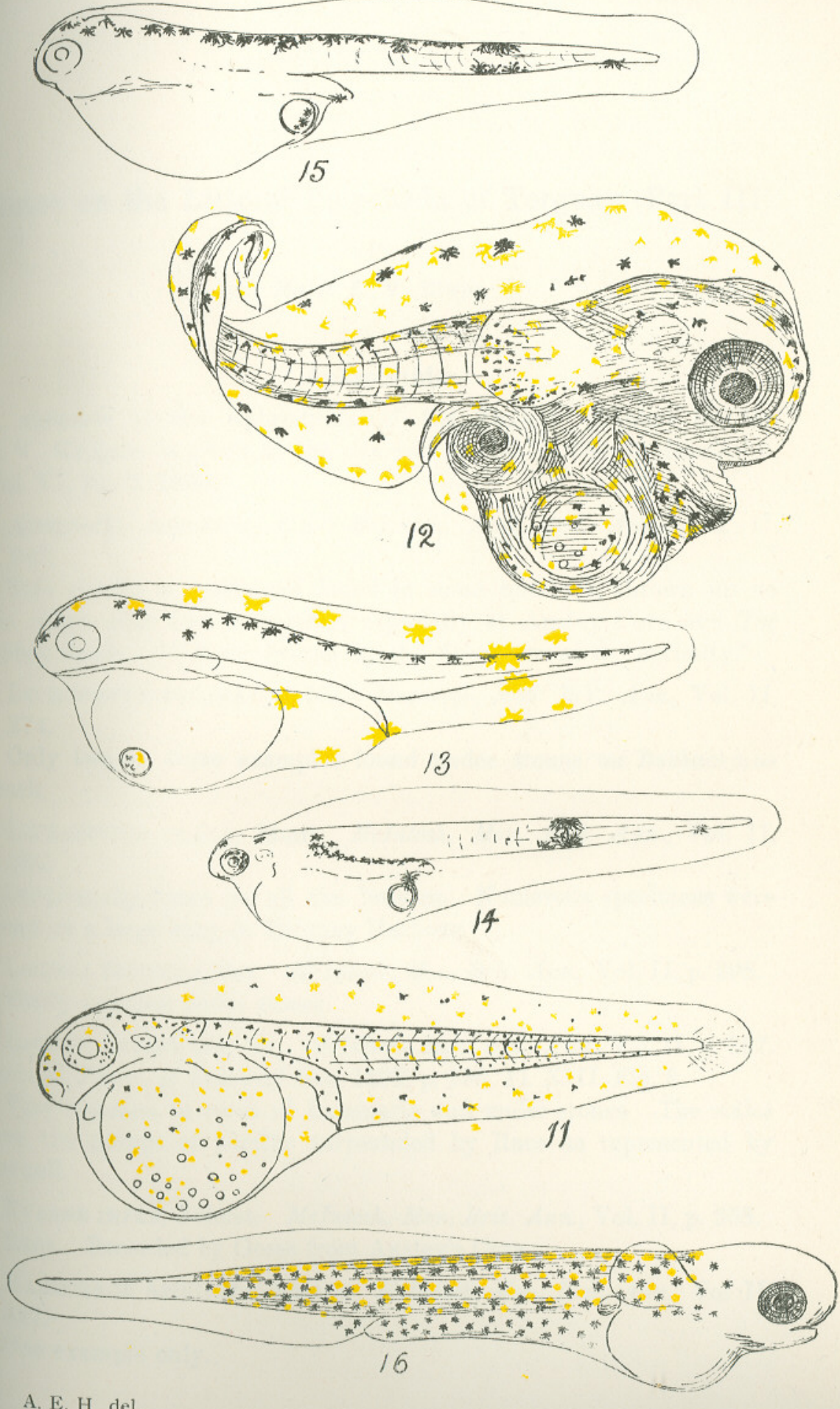

A. E. H. del. 